\title{
Seeing Things Differently: the use of mobile app interpretation and its effect on visitor experience at two heritage sites in Aotearoa New Zealand
}

\author{
By Jessica Aitken
}

A dissertation submitted to Victoria University of Wellington in partial fulfilment of the requirements for the degree Master of Museum and Heritage Studies.

Victoria University of Wellington 


\section{Abstract}

The practice of contemporary heritage interpretation has seen increased investment in digital technologies and more recently in mobile applications. However, few empirical studies assess how effective mobile apps are to the visitor experience of heritage sites. What kind of visitor experience do mobile apps provide? How do mobile apps deliver on the aims of interpretation for heritage sites? What types of apps work best? What are the challenges for developers and heritage professionals?

A qualitative research approach is used to examine two case studies; High Street Stories: the life and times of Christchurch's High Street Precinct and IPENZ Engineering Tours: Wellington Heritage Walking Tour. These case studies ask what kind of experience mobile apps offer as an interpretation tool at these heritage sites. To investigate the topic, email interviews were carried out with heritage professionals and digital developers; together with qualitative interviews with visitors recruited to visit the case study sites using the mobile applications.

This study explores two current examples of mobile app technology in the heritage sector in a New Zealand context. The results of this study aim to augment current literature on the topic of digital interpretation. This study seeks to offer heritage managers and interpreters some key factors to consider when making decisions regarding the methods used to present and interpret heritage sites to visitors and in developing new interpretation and digital strategies that include mobile applications. Although each scenario presents its particular set of considerations and all heritage sites are different, it is hoped these recommendations can be applied and offer working models and strategies.

\section{Keywords:}

Heritage - cultural landscapes - heritage sites — interpretation practice - digital interpretation — visitor experience — mobile application — heritage tourism - built heritage 


\section{Acknowledgements}

To Lee Davidson, for her guidance, encouragement, and patience throughout this dissertation and the past two years. Thanks also to the staff in the Museum and Heritage Studies program who make this all possible.

To Shannon Wellington, who generously shared her expertise and her time. Thank you for the valuable conversations and your guidance.

To Karen Astwood, Zoe Roland, Gun Lee, and Glen Barnes, for taking the time to share their specialist knowledge and experience. To the visitors, for their comments, insights and for so generously giving their time.

To my classmates, for their friendship, empathy and coffee breaks.

To my family, Rob, Anna, Georgina, David, and Erica, for everything.

To Dean, for his patience, practical advice, unswerving support and just the right amount of tough love to keep me focused.

And to Bella, I have finally finished my "homework!" 


\section{TABLE OF GONTENTS}

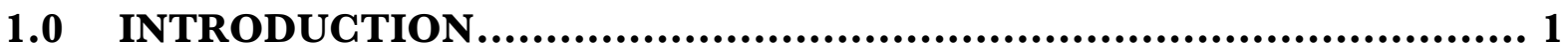

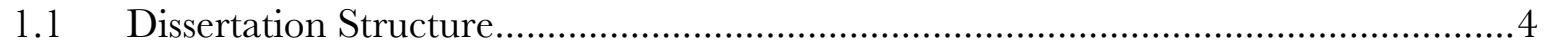

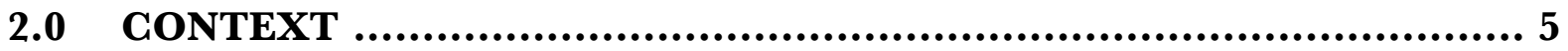

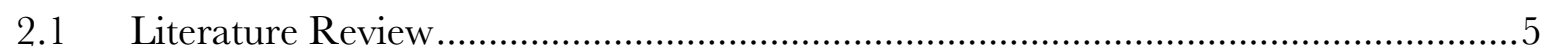

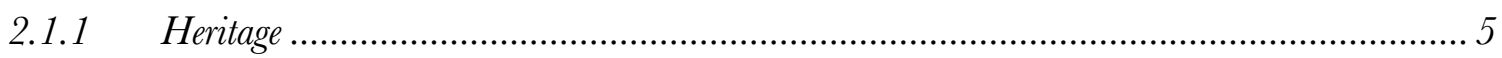

2.1.2 Interpretation Theory $\&$ Practice .................................................................................. 7

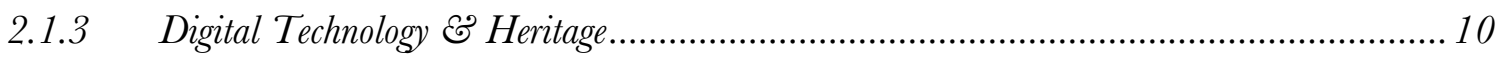

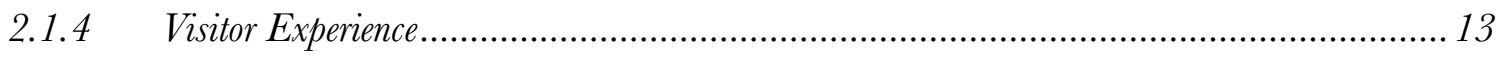

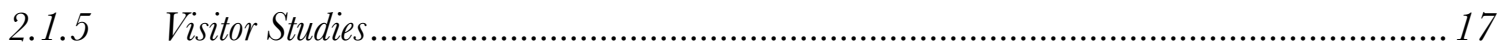

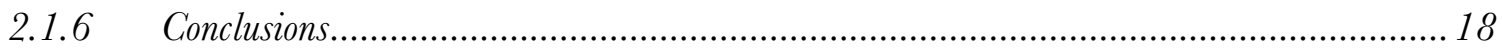

3.0 RESEARGH DESIGN..........................................................19

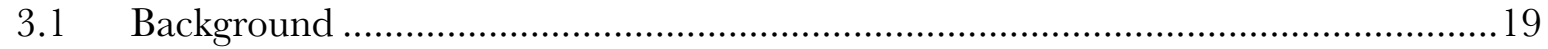

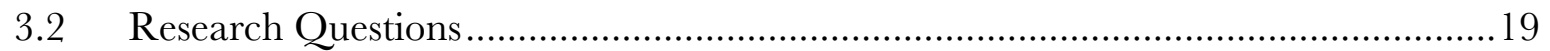

3.4 Mobile Application Appraisal \& Case Study Selection............................................22

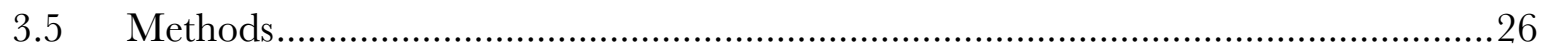

4.0 THE GASE STUDIES .................................................... 30

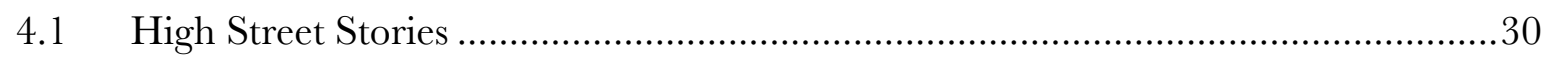

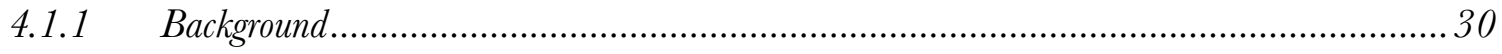

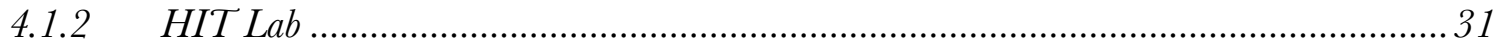

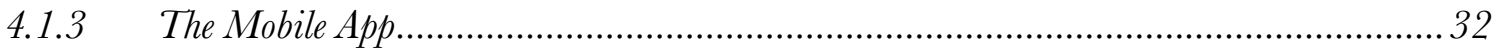

4.2 IPENZ Engineering Tours: Wellington Heritage Walking Tour ............................35

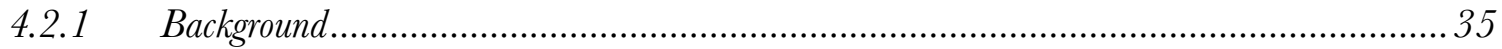

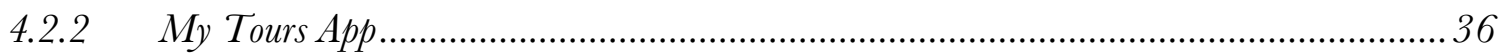

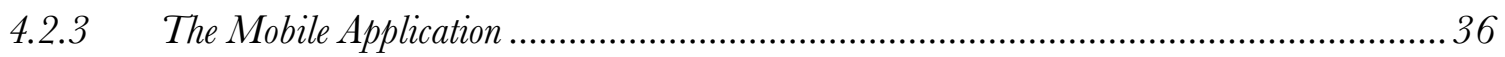

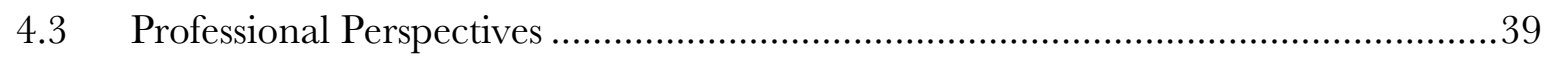

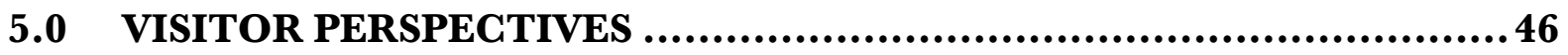

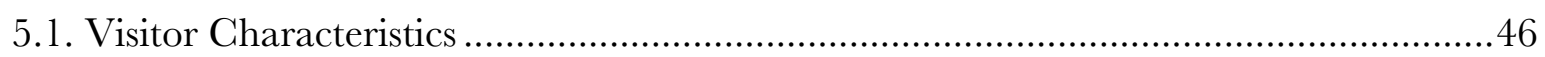

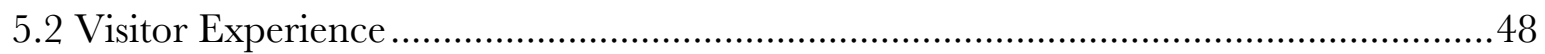

5.2.1 Intangible Values and Personal Connections …........................................................... 48

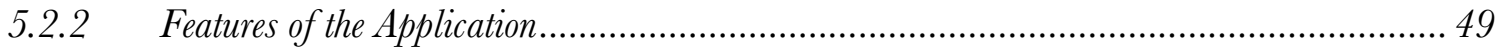

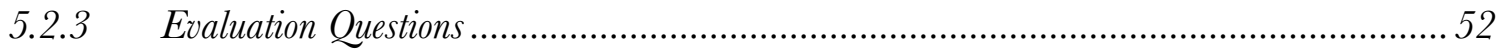




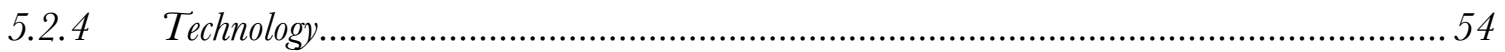

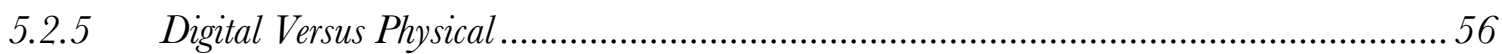

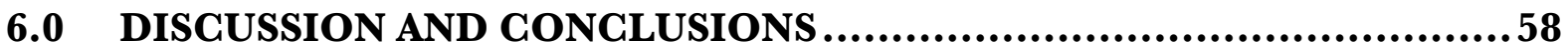

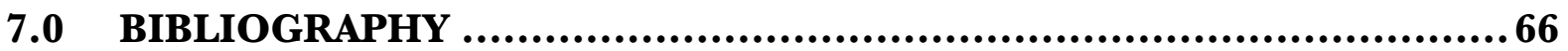

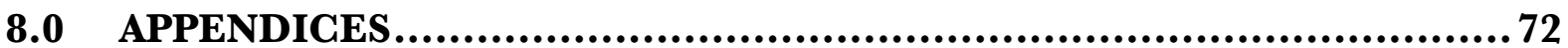

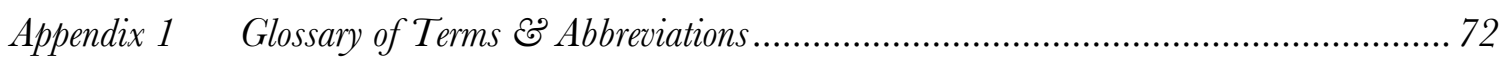

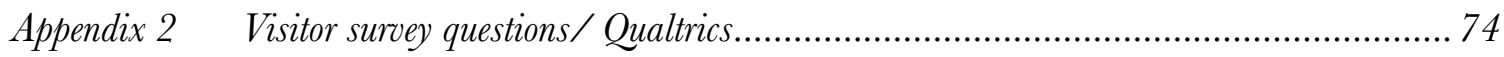

Appendix $3 \quad$ Email interview questions for heritage and design professionals ................................ 76

Appendix $4 \quad$ Prompts used for visitor interviewe........................................................................ 79 


\section{List of Illustrations}

Figure one: HSS: Menu page.

Figure two: HSS: Sorting stories by theme. 33

Figure three: HSS: Layout showing all stories. 33

Figure four: HSS: Page layout for each story. 33

Figure five: HSS: Augmented reality feature, streetview. 34

Figure six: HSS: Augmented reality feature, selecting a story. 34

Figure seven: HSS: Map view and story locations. 34

Figure eight: IPENZ: Menu page. 38

Figure nine: IPENZ: Page layout for each story. 38

Figure ten: IPENZ: Social media options and icons for each story page. 38

Figure eleven: IPENZ: Map view and tour layout. 38

List of Tables

Table one: Visitor characteristics and backgrounds. 47 


\subsection{INTRODUCTION}

Some have described the beginning of the third millennium as a 'technological revolution.' The digital sphere has become a part of everyday life and brought with it a rapid expansion of media technology, increasing access to the internet and unprecedented online presence and connection. Digital technology is changing the way people interact and communicate with the world. Museums have already adopted a range of new media tools, in exhibitions, interpretation, and in social media and online. It has seen almost all institutions develop websites and maintain social media accounts, making information readily available and continuously updated. The potential for digital platforms to increase accessibility is described by many authors who envision a museum without walls, where information and knowledge are available to visitors on site and online and driven by objectives such as 'outreach, dissemination of knowledge, access and social inclusion.'2

Museums have learnt a great deal from their interactions with the web. More has been discovered about visitors, the power of open access data, and the opportunity for discussion through social media. It has helped in bridging the gaps between museums, their content and their audiences. It has aligned with the new museology model, which focuses on the social role of museums and new styles of communication; it promotes an open institution, asks for active participation of the visitor, and seeks to be a platform that generates social change. ${ }^{3}$ The focus has shifted from the museum as an ivory tower to being influenced by audiences and communities. The new museum favours dialogue, interpretation, and experience. ${ }^{4}$

Contemporary interpretation practice has seen an increased investment in digital technology. Touch-screens and interactives are now the standard in most new exhibitions, and there is more experimentation with $\mathrm{AR}$ and VR technologies and immersive experiences. Today, it seems, is the age of the smartphone. Since being first introduced in the 1980s, mobile phones have evolved regarding both their physical appearance and technical specifications. From their inception as a phone that could be transported they are now capable of a multitude of

\footnotetext{
1 Anamaria Tomiuc, "Navigating Culture: Enhancing Visitor Museum Experience through Mobile Technologies," Fournal of Media Research 3.20 (2014): 33.

${ }^{2}$ Konstantinos Arvanitis, "Museums outside Walls: Mobile Phones and the Museum in the Everyday," in Museums in a Digital Age, ed. Ross Parry, (New York: Routledge, 2010), 170.

3 Tomiuc, 34.

4 Tomiuc, 34.
} 
functions. "Smartphone" is the term used to refer to the "new class of mobile devices that provide integrated capabilities including communication, computing and mobile services like voice communication, messaging, personal information management applications and wireless communication. ${ }^{5}$ Smartphones are essentially a universal mobile terminal in the palm of your hand which combines the features of a phone with those of a computer and other personal consumer devices like media player, digital camera, and GPS navigation unit. Today, smartphones are used to text, talk, play games, take photos, play music, shop, do banking, monitor fitness levels, connect to social media, give you GPS directions, and a multitude of other activities.

Deloitte describes smartphones as 'the most personal of consumer electronic devices: the most constant companion, the most personal of choices, the most customised and reflective of the owners, the least likely to be shared with other users and the most frequently looked at.' 6 Tallon argues that smartphones are an ideal tool for museums: they are 'already in the hands of a wide public, comfortable and literate with their modes of engagement,' users have 'a ready-made, intuitive relationship,' and because the visitor already owns them, these platforms provide somewhat cost-effective interpretative solutions. ${ }^{7}$ In New Zealand, smartphone ownership is increasing and fast becoming the nation's most popular device with almost three-quarters of adults now owning or having access to one. ${ }^{8}$ With the exception of smartphones, the daily use of all other devices is trending downwards. ${ }^{9}$ The frequency of use for smartphones is equally high amongst the young and the middle-aged with 94 percent of those aged 18 to 34 and of those aged 35 to 54 reporting daily use of their smartphone and a slight drop to 79 percent of those aged $55+.{ }^{10}$

Mobile applications are typically a small, specialised program downloaded onto mobile devices. They are the primary way to deliver the features we associate with smartphone use:

\footnotetext{
5 Tomiuc, 35.

${ }^{6}$ Paul Lee, Duncan Stewart and Cornelia Calugar-Pop, "Deloitte: Technology, Media and Telecommunications Predictions, 2014" Deloitte, accessed 10 October 2016, https://www2.deloitte.com/content/dam/Deloitte/global/Documents/ Technology-Media-Telecommunications/dttl_TMT_Predictions-2014-lc2.pdf

${ }^{7}$ Loïc Tallon, "Introduction: Mobile, Digital, and Personal," in Digital Technologies and the Museum Experience: Handheld Guides and Other Media, eds. Loï Tallon, and Kevin Walker (Lanham: AltaMira Press, 2008), xvii.

8 Smartphone ownership has had a 46 percent increase since 2013. Research New Zealand, A Report on a Survey of New Zealanders' Use of Smartphones and other Mobile Communication Devices 2015, (Wellington: Research NZ, 2015), 3.

${ }_{9}$ Research NZ, 3.

10 Research NZ, 9.
} 
our email, social media, news, games, maps, etc. Internationally, users spend $87 \%$ of their smartphone time in apps, rather than their web browser, and it is projected there will be nearly 269 billion app downloads in 2017. ${ }^{11}$ Whether it's gaming, social media, music or photography, mobile applications have changed the way we communicate and consume content online. The Apple AppStore, the first of the modern smartphone app stores that we would recognise as such, was launched with iOS 2 in July 2008. Since then, apps have come into the mainstream and today, there are three main app stores: Google Play, Windows, and Apple. Between the three, they offer 5 million apps available for download: 2.2 million on Google Play; 0.7 million for Windows; and, 2 million for Apple. ${ }^{12}$ In December 2016, the three most popular types of apps in the AppStore were: games; business apps; and, education apps. ${ }^{13}$ However, it is estimated that $70 \%$ of downloaded apps are deleted after less than 72 hours. ${ }^{14}$

We sometimes forget that museums are also home to the remnants of past technologies and not just in their collections. The evolution of exhibitions has left Ethernet ports hidden behind panels, and stockpiled DVD players and CRT TVs in back storerooms. Sometimes visitors are perplexed when the screen they press doesn't respond. Often technologies and the expectations of visitors move faster than museums can keep up. Visitors can download and delete the newest app on a whim, but museums must live with their investments far more long term.

With mobile applications being readily adopted by museums and heritage intuitions it is becoming increasingly important to understand how the promises made by digital technology compare to the reality of the experience they provide. This research uses two New Zealand heritage sites with mobile app interpretation to investigate what kind of experience mobile apps offer as an interpretation tool; High Street Stories: the life and times of Christchurch's High Street Precinct and IPENZ Engineering Tours: Wellington Heritage Walking Tour. The aim of this thesis is to study the value of mobile applications in heritage interpretation using qualitative

\footnotetext{
11 Statista, "Number of mobile app downloads worldwide from 2009 to 2017," accessed 10 January 2017, https://www.statista.com/statistics/266488/forecast-of-mobile-app-downloads/

12 Statista, "Number of apps available in leading app stores as of June 2016," accessed 1 October 2016, https:/ /www.statista.com/statistics/276623/number-of-apps-available-in-leading-app-stores /

13 Statista, "Most popular Apple App Store categories," accessed 10 October 2016, https://www.statista.com/statistics/270291/popular-categories-in-the-app-store/

${ }^{14}$ John Dye, "77 percent of users never use an app again 72 hours after installing," Android Authority, accessed 2 October 2016, http://www.androidauthority.com/77-percent-users-dont-use-an-app-after-three-days-678107 /
} 
methodology. Email interviews have been carried out with heritage professionals and digital developers; and, qualitative interviews were conducted with visitors recruited to visit the case study sites using the mobile applications, to investigate both sides of the topic.

\subsection{Dissertation Structure}

The following chapters examine the literature that frames this research, then, presents the research aims and methodology in more detail and ends with the research results and discussion and conclusions.

\section{Chapter two}

Chapter two begins with a literature review, to examine the intellectual context of mobile apps in heritage interpretation. It draws on relevant and recent research to examine the key themes of the research and provide the framework for this investigation.

\section{Chapter three}

Research aims and methodology are discussed in more detail in chapter three. This chapter outlines the research questions and the methods used to conduct the study. It presents the visitor survey and interviews, and the email interview questions for heritage and design professionals. It includes an appraisal of current heritage applications on offer in Aotearoa and the process of case study selection.

\section{Chapter four}

This chapter looks at the two case studies, with a brief history of each project, the parties involved in the development, and a discussion of the mobile apps. The chapter finishes by presenting the professional perspectives on the two applications.

\section{Chapter five}

Results from the research carried out for this study are presented, focusing on the visitor perspective and experience discussed in the visitor questionnaire and interviews. It is presented using the key themes that were revealed through the analysis of the data.

\section{Chapter six}

Finally, chapter six discusses the findings in detail, including recommendations for further research, recommendations for heritage practitioners, and conclusions of the research project. 


\subsection{GONTEXT}

\subsection{Literature Review}

There is fast becoming an established body of research that examines digital technology and the GLAM sector. However, the use of mobile applications at heritage sites is relatively new and an indicator that more empirical research is needed to better understand the value of digital applications in the interpretation and presentation of heritage. This literature review draws on several related fields of academic study to establish a framework for this research, looking first at a general heritage studies context then focusing on four main areas. Interpretation is discussed beginning with its theoretical origins and then its relationship with visitor experience. The review then looks at how digital technology has been adopted into this process. Visitor experience is examined, drawing on the work of Laurajane Smith to examine the performance of meaning- and heritage-making by visitors to heritage sites. Related to this, heritage tourism is discussed with consideration of the negative and reductive way tourists and tourist activities have previously been portrayed. Finally, the review looks to visitor studies as a way to bridge the gap between theory and practice.

\subsubsection{Heritage}

Lowenthal argues that heritage is history with the pain edited out. ${ }^{1}$ In his writing, he provides analysis through the interplay between definitions of history and heritage, where 'history explores and explains pasts grown ever more opaque over time,' but 'heritage clarifies pasts so as to infuse them with present purposes. ${ }^{2}$ Heritage is seen as a kind of "Distory" (Disney history), a 'popular expression of historical nostalgia' which privileges some narratives and downplays others. ${ }^{3}$ The heavily imbued notion of nostalgia means the past is viewed as intrinsically good, emphasising themes like community and success but rarely depicting concepts like alienation, despite being prevalent in New Zealand history. ${ }^{4}$ As a colonised country New Zealand is host to a number of uncomfortable histories. There are many complex stories. Some we may want to forget or remember differently: 'we collude in our ignorance of pasts that will shame or wound us. Partial amnesia is necessary to ongoing life

\footnotetext{
${ }^{1}$ Conal McCarthy, “Te Ara o Nga Tupuna Maori Heritage Trail/Te Aro Pa, 39 Taranaki St, Wellington,” New Zealand Fournal of History 43.1 (2009): 114.

2 David Lowenthal, Possessed by the Past: The Heritage Crusade and the Spoils of History, (New York: Free Press, 1996), xi.

${ }^{3}$ McCarthy, 114.

${ }^{4}$ Alexander Trapeznik and Gavin McLean, "Public History, Heritage and Place," in Common Ground? Heritage and Public Places in New Zealand, ed. Alexander Trapeznik, (Dunedin: University of Otago Press, 2000), 15-16.
} 
[and] we all crave a past we can love.'5 Lowenthal points out, this 'selective oblivion,' whether it is enforced upon us or voluntary, has very real consequences for 'present action and future purpose. ${ }^{7}$ It is imperative that these sites and stories become visible and are interpreted in a way that is accessible and engaging for a general public.

Remembering the past is a crucial part of one's sense of identity: 'memory validates personal identity' and 'history perpetuates collective self awareness. ${ }^{77}$ Memories and histories are not simply what happened, they are not unproblematic faithful retellings of facts, but are constructed in the present and molded by selective interpretation of heritage resources. The flaws of heritage stem from the central role it plays in community and identity. ${ }^{8}$ When identity is based on a select version of history and at a national level 'incorporates commonly agreed-upon cultural values' it enables a sense of belonging and establishes a linguistic framework where we can 'speak of 'our' heritage or 'national' heritage.'

According to Smith, 'there is, really, no such thing as heritage.' ${ }^{10}$ Heritage is not a thing with clearly delineated meanings and values, but an 'inherently political and discordant' practice. ${ }^{11}$ A concept she terms the "Authorised Heritage Discourse" (AHD) performs the 'cultural work' of the present and is employed by different groups and individuals for separate purposes and with varying degrees of hegemony and legitimacy. ${ }^{12}$ The AHD defines heritage as 'aesthetically pleasing material objects, sites, places and/or landscapes that are nonrenewable.' ${ }^{13}$ This sense of fragility means that it must be protected, cared for so that it may be inherited by future generations. According to the AHD, such protection can only be afforded 'under the stewardship of particular forms of expertise.'14 Decisions regarding the cultural values that determine a sense of place and identity are determined by levels of wealth and education, which inevitably privilege the vestiges and relics of the rich and elite. ${ }^{15}$

\footnotetext{
5 David Lowenthal, 'Heritage and Its History: Menaces of the Much-Loved Past', Keynote Address to the Research Libraries Group 1999 Annual Membership Meeting, accessed 15 May 2015, http://www.rlg.org/annmtg/lowenthal99.htm, 2.

6 David Lowenthal, 'Heritage and Its History,' 2.

7 David Lowenthal, The Past is a Foreign Country, (Cambridge; New York: Cambridge University Press, 1985$), 213$.

${ }^{8}$ Lowenthal, The Past is a Foreign Country, 102.

9 Trapeznik and McLean, 15.

${ }^{10}$ Laurajane Smith, The Uses of Heritage, (London and New York: Routledge, 2006), 11.

11 Laurajane Smith, The Uses of Heritage, 11.

12 Smith, The Uses of Heritage, 11-13.

13 Laurajane Smith, “The cultural 'work' of tourism," in The Cultural Moment in Tourism, (New York: Routledge, 2012$), 212$.

14 Smith, "The cultural 'work' of tourism," 212.

15 Trapeznik and McLean, 21.
} 
Therefore, particular social and cultural understandings about culture are maintained, inherited from eighteenth- and nineteenth-century antiquarian interest and ensured by the educated professional expert. This has followed the Western notion of privileging that which is "important" and "worthy" and tends to favour the monumental over the quotidian. The AHD 'takes its cue from the grand narratives of Western national and elite class experiences, and reinforces the idea of innate cultural value tied to time depth, monumentality, expert knowledge, and aesthetics. ${ }^{16}$

With these discussions in mind, the next section turns to how we interact with heritage, starting from a managerial level in the form of interpretation and presentation of heritage sites, through to visitor engagement, meaning-making, and performance in the form of visitor experience.

\subsubsection{Interpretation Theory \& Practice}

In a broad sense, visitors at heritage places can be thought of as 'in dialogue' with the places, objects, and landscapes they visit. ${ }^{17}$ Part of this dialogic relationship is facilitated by the tools used by heritage management to engage with visitors, namely, interpretation. Some of the core ideas of heritage interpretation were laid down by Tilden in his seminal work Interpreting our Heritage. Although it was written in 1957, many authors consider his ideas to hold relevance today, and they have been built on by subsequent theorists. Coming from a journalist background, Tilden understood the power of stories and their appeal to audiences. He advocated a move from an instructional style to interpretation that developed from 'revelation based upon information.' ${ }^{18}$ For Tilden, the aim of interpretation 'is not instruction, but provocation.' ${ }^{19}$ This idea of revealing and provoking ideas widens the scope from pure conservation of material culture to include thinking, values, and feelings. It demands a range of information sources that speak to visitors on different levels. Tilden's famous dictum was: 'through interpretation, understanding; through understanding, appreciation; through appreciation, protection. ${ }^{20}$

\footnotetext{
16 Smith, The Uses of Heritage, 299

17 Russell Staiff, Re-Imagining Heritage Interpretation: Enchanting the Past-Future, (Farnham, Surrey \& Burlington, Vermont: Ashgate Publishing Group, 2014), 3.

${ }_{18}$ Freeman Tilden, Interpreting our Heritage, (North Carolina: University of North Carolina Press, 1977), 9.

19 Tilden, 32.

20 A quote from an obscure administrative manual for U.S. National Park Service rangers, Tilden, 38.
} 
Several authors have built on Tilden's original six principles. Beck and Cable view Tilden's principles as remaining the standard regarding a philosophical foundation, stating that some of the principles are timeless, but some, need a revision for current perspective. They add nine more principles or "gifts," framing their work within the early literature on interpretation but updated for the twenty-first century to include high technology. They describe interpretation as 'an educational activity that aims to reveal meanings about our cultural and natural resources. ${ }^{21}$ It is a process rather than something that is done, 'a rendering' where visitors can see, learn, experience and be inspired by, first hand. ${ }^{22}$ They believe that effective interpretation comes from knowing the audience. This is achieved through visitor surveys which move beyond simple demographics, to include values, motivations, attitudes and satisfactions. ${ }^{23}$

Another author to build on Tilden's work is Sam Ham, who distils Tilden's principles to four essentials. ${ }^{24}$ His theory of thematic interpretation is illustrated using an acronym for the essential elements of successful interpretation: TORE, that is, Thematic, Organised, Relevant, and Enjoyable. ${ }^{25}$ Jimson, a New Zealand author and practitioner, plays on this idea of fun and entertainment. He argues that interpretation must also 'facilitate positive social interaction, including entertainment.'26 For him, interpretation should 'aim to combine enjoyment with learning... if visitors are having a pleasurable time they are more likely to engage with the museum content. ${ }^{27}$ Hooper-Greenhill echoes this sentiment when she suggests that where museums disappoint is when they are seen as 'worthy but dull.'28 The challenge is to present museums as 'worthy and fun.'29

\footnotetext{
${ }^{21}$ Larry Beck and Ted T. Cable, The Gifts of Interpretation: Fifteen Guiding Principles for Interpreting Nature and Culture, (Illinois: Sagamore Publishing, 2011), xvii.

22 Beck and Cable, xxi.

${ }^{23}$ Beck and Cable, 6.

${ }^{24}$ Sam H. Ham, Environmental Interpretation: A Practical Guide for People with Big Ideas and Small Budgets, (North American Press, 1993).

${ }^{25}$ Sam H. Ham, Making a Difference on Purpose, (Colorado: Fulcrum Publishing, 2013).

${ }^{26}$ Kerry Jimson, "Translating Museum Meanings: a case for interpretation," in The International Handbooks of Museum Studies: Museum Practice, First Edition, ed. Conal McCarthy, (John Wiley \& Sons, Ltd., 2015), 535. He also suggests looking to Weil 1998 on this point.

27 Jimson, 536.

28 Eileen Hooper-Greenhill, Museums and Their Visitors, (London: Routledge, 2013), 33.

29 Hooper-Greenhill, 33.
} 
Staiff acknowledges the prominent position that Tilden's work has held and the influence it has had on several authors. However, he finds it problematic in the way it privileges heritage interpretation over other forms of interpretation, considering it separate and of a 'new kind.'30 Staiff urges us to think of it in relation to all other forms of interpretation, from scholarly interpretation of an artwork, to media interpretation of events, which he considers to be just one activity along a huge continuum of activities that arise because of representation and the urge to make meaning. ${ }^{\text {'31 }}$ By considering heritage interpretation as somehow 'special,' it becomes 'estranged' from these other forms and the cumulative theoretical insights offered by scholars in representation studies such as Umberto Eco, Stuart Hall, and Edward Said. ${ }^{32}$

Staiff dismantles Tilden's concept that interpretation is 'revelation based on factual information,' that interpreters are 'revealers' who 'reveal meaning and relationships. ${ }^{33}$ The issue is the idea that something is 'hidden' behind the human perceived material essence of an object, and what is hidden is considered to be its 'truth.' He ties this to representation and truth as philosophised in the West by Plato and the 'appeal to truth and knowledge beyond physical reality. ${ }^{34}$ Until recently, this type of thinking has been commonplace, where meaning was considered inherent in objects and sites, interpretation was simply the tool in which to tease out the meaning embedded within. Meaning exists outside of the physical object, 'it resides in the symbols, signs, stories, rituals and so forth that we, the viewers, attach.' ${ }^{35}$ Different visitors can have different interpretations of the same object, and a visitor can entertain several different interpretations.

Staiff is particularly critical of 'the emergence of heritage interpretation orthodoxy' developed from Tilden's work and solidified through international conferences, national interpretation associations and several key texts from the 1980s, which places education and learning at the centre of interpretation activities. ${ }^{36}$ The pervasiveness of the education paradigm has been identified and critiqued by several authors, and their discussion is important when

\footnotetext{
30 Staiff, 34-35.

${ }^{31}$ Staiff, 35.

32 Staiff recommends Said 1985, Eco 1987, Hall 1997, 35.

33 Tilden, 8-9.

34 Staiff, 36.

35 Staiff, 31.

36 Staiff, 9.
} 
considering contemporary interpretation techniques. ${ }^{37}$ While education is not unimportant it 'is stifling and restrictive in its own way.' 38 Heritage sites that focus heavily on educational aspects of interpretation disregard the possibility that visitors may be seeking an experience other than learning. Smith suggests that people go to heritage sites to feel and the failure to understand the emotive aspects of heritage and museum visiting 'simply reinforces the idea that visiting is, or should primarily be, about learning. ${ }^{39}$ The education paradigm serves to obscure the emotional aspects of visitor experience and 'downplays the ability of visitors to use the museums in developing their own critical or political insights beyond that determined by the museum curator or heritage professional.'40

\subsubsection{Digital Technology $\mathbb{E}$ Heritage}

Within museum and heritage studies scholarly papers tend to focus on digital technology as part of museum education and visitor studies. Literature focuses on examining the emergence and impact of social media and social networking on museums and looks at digital technology as offering new forms of communication, which create opportunities for participation and cocreation. A number of authors introduce Malraux's 1947 treatise Le Musée Imaginaire as a framework for the impact of new media on museums. ${ }^{41}$ This framework envisions a museum without walls and Malraux's theories can be seen in the concept of the virtual museum. ${ }^{42}$ Parry frames Malraux's thesis as the idea of technology liberating and reconfiguring the museum from its traditional modes of presentation.' 43 The museum without walls is one 'that makes its information and knowledge available both to on-site and remote visitors. ${ }^{34}$ New media, it is argued, can 'extend and reconceptualize how museums and their collections can engage with society. ${ }^{95}$ Based on this theoretical framework it is no surprise then that many recent projects incorporate a digital aspect, ranging from within museum exhibitions, to interpreting heritage sites in light of the promises made by digital technology.

\footnotetext{
37 Staiff, Smith, Poria et al.

38 Staiff, 9.

${ }^{39}$ Laurajane Smith, "Theorising Museum and Heritage Visiting," in The International Handbooks of Museum Practice, ed. Conal McCarthy, (New York: John Wiley \& Sons, Ltd., 2015), 477.

40 Smith, "Theorising Museum and Heritage Visiting," 478.

${ }^{41}$ Parry, Arvanitis, Wellington and Oliver.

42 Shannon Wellington and Gillian Oliver, "Reviewing the Digital Heritage Landscape - The Intersection of Digital Media and Museum Practice," in The International Handbooks of Museum Studies: Museum Practice, First Edition, ed. Conal McCarthy, (John Wiley \& Sons, Ltd., 2015), 583.

43 Ross Parry, ed., Museums in a Digital Age, (New York: Routledge, 2010), 119.

${ }^{44}$ Konstantinos Arvanitis, "Museums outside Walls: Mobile Phones and the Museum in the Everyday," in Museums in a Digital Age, ed. Ross Parry (New York: Routledge, 2010), 170.

45 Wellington and Oliver, 583.
} 
Falk and Dierking examine the ways the characteristics of digital media benefit the heritage experience. They suggest that digital media has a 'power to juxtapose and visually and aurally connect ideas [and] is an excellent vehicle for presenting abstractions or functionally invisible phenomenon. ${ }^{46}$ This visual and aural characteristic 'can support and complement the presentation and interpretation of objects and phenomena in ways that the objects and phenomena alone may not be able to do. ${ }^{\text {'47 }}$ It can illustrate concepts that are hard to express in traditional static displays, such as change and dynamism. Digital media also holds the ability to visually place objects within their 'appropriate historical and/or cultural contexts,' which in turn helps visitors to better understand objects and to 'transcend their concrete characteristics. $^{4} 4$

The Museum Association in the UK carried out Mobile Surveys in 2012 and 2013 investigating how museums are using mobile technology. These studies offer insights into the current culture of mobile usage in museums and at historic sites. The surveys focus on the institutional point of view, revealing some of the priorities held by museums and their historic site curators and managers. They found half of the 175 respondent institutions have a mobile offer. The most popular of these were QR codes at $63 \%$, followed by museum provided audio tours $(46 \%)$, mobile optimised websites $(45 \%)$, and then smartphone apps for Apple $(39 \%)$ and Android (36\%). ${ }^{49}$ The main objectives they identified for using mobile technology were:

- to provide additional content to visitors $(68 \%)$

- to create a more engaging visitor experience $(67 \%)$

- to attract new visitors $(33 \%)$

- $\quad$ to keep up with visitor demand $(28 \%)$

- to widen access to people with special needs $(27 \%) .{ }^{50}$

A similar research project conducted by the University of Leeds focused on a variety of digital media platforms, rather than specifically mobile apps. The aim of the study was to provide a critical review of digital engagement and how it shapes cultural experiences in the context of

${ }^{46}$ H. F. Falk and L. D. Dierking, Museum Experience Revisited, (Washington: Left Coast Print, 2012), 119.

47 Falk and Dierking, Museum Experience Revisited, 120.

48 Falk and Dierking, Museum Experience Revisited, 120.

${ }^{49}$ Museum Association, Mobile Survey 2013, (London: Museum Association, 2013), accessed 5 Septemeber 2015, www.museumsassociation.org/download?id $=1025016$

50 Statistics qtd in Tomiuc, 37. 
museums, galleries, and heritage. ${ }^{51}$ It provided a range of recommendations for professionals, concluding, 'digital has the power to detract from, as well as enhance the value of heritage. 52

The Smithsonian's National Air \& Space Museum carried out a study investigating their visitors in preparation for mobile developments. The focus of the survey was 'to determine the extent to which visitors... have smartphones that can access the internet, how they are using their devices in the museum and their satisfaction with the museum experience. ${ }^{53}$ They found that visitors were already using their phones as part of museum-going behavior; this was primarily taking photos and searching to discover more information. Another key finding was that around half of the visitors surveyed who own a smartphone say they would prefer to use their own device over a museum one. Reasons for this include, ease and familiarity, hygiene and the convenience of already possessing an interpretation tool, with no need to collect or return a guide. A similar study carried out across The Tate, The National Gallery, and the Imperial War Museum found that attitudes to mobile use in museums varied across the three venues. ${ }^{54}$ While most visitors expected it, some questioned how appropriate it was to use mobile devices in a museum. Others were, in fact, strongly opposed, explaining that it detracted from the experience of the objects themselves. ${ }^{55}$

While expressing the potential for new media in heritage contexts, authors like Wellington and Oliver also suggests a more tentative approach to digital interpretation, rather than pursuing 'technology for its own sake. ${ }^{56}$ They raise valuable questions about what the incorporation of digital technology might do to heritage interpretation. They question whether there is a 'digital divide' where access to 'a particular interpretive/knowledge layer' is available only to those with the digital technology and literacy to use it. ${ }^{57}$ The philosophy set out by the new museology, which many cultural institutions now align to, advocates for democratised access where museums have an obligation to reach out to a range of audiences

\footnotetext{
${ }^{51}$ University of Leeds, Experiencing the Digital World: The Cultural Value of Digital Engagement with Heritage, (2014), accessed 10 April 2016, www.digitalheritage.leeds.ac.uk

${ }^{52}$ University of Leeds, 2014.

${ }^{53}$ Smithsonian Institute, Mobile Usage at the National Air and Space Museum, (Washington: Office of Policy and Analysis, 2013$), 2$.

${ }_{54}$ Andrew Lewis, "What do visitors say about using mobile devices in museums?" Victoria and Albert Museum, published 13

March 2013, http://www.vam.ac.uk/blog/digital-media/museum-visitors-using-mobile.

55 Lewis, 2013.

56 Wellington and Oliver, 587.

57 Wellington and Oliver, 589.
} 
and not privilege one over the other. Wellington and Oliver are quick to point out a notion often overlooked: 'there are different audiences not interested in all things digital. ${ }^{58}$ This could be true for those who enjoy heritage sites for the very fact that they are outdoors and can "unplug" from a digital and technology-saturated world.

Wellington and Oliver refer to the growing digital imperative whereby institutions are determined to use and implement digital heritage in a 'rush to remain digitally relevant.'59 Falk and Dierking are also quick to warn against being seduced by the 'excitement and novelty' of new digital technology, and the idea that it will make it easier for museums to tell stories to the public. We must still consider them as "tools" which, in the end, "will be selectively used by the public. ${ }^{90}$ Digital media is not exempt from the principles applied to more traditional means, such as wall labels. Visitors 'will only spend time watching/listening/interacting with media if they are interested in the topic and motivated to learn more; if they are not, no matter how glitzy, expensive, or elaborate the media, they will not pay attention.' 61

Much of the literature talks extensively about the potential of digital technology and the theoretical context in which it exists. Few studies, however, go beyond this promise of potential, and there are even fewer empirical studies into specific cases in the heritage sector in a New Zealand context. Despite the lack of empirical foundation, digital technology and especially mobile applications, are increasingly being adopted as an interpretation tool. There is a clear need to examine the perceived potential of digital apps as interpretation tools against the experience of visitors who use them. To do this, there needs to be an understanding of what it is that visitors $d o$ at heritage sites and the relationship between interpretation and visitor experience.

\subsubsection{Visitor Experience}

Heritage is not simply found with inherent meaning, and it is important to consider the cultural meanings that are created by both heritage management through preservation and

\footnotetext{
58 Wellington and Oliver, 589.

59 Wellington and Oliver, 587.

${ }^{60}$ Falk and Dierking, Museum Experience Revisited, 122.

${ }^{61}$ Falk and Dierking, Museum Experience Revisited, 122.
} 
interpretation, and, by the meanings that are constructed by visitor engagement. ${ }^{62}$ Heritage should be considered a verb rather than a noun: "heritage' is something we do, rather than something that is. ${ }^{93}$ Heritage has become a significant component of the tourism industry with heritage sites becoming choice travel destinations; therefore, it is important to consider tourists and tourist activities in productive and meaningful ways. Smith, Waterton, and Watson explore the cultural, political and economic interrelations between culture, heritage, and the tourist industry. They suggest that tourism literature has focused more on the supplyside perspective and cultural tourists have been seen for their interest in cultural tourism products and/or their economic worth as a sought-after market segment.' 64 Compounding this is the trend to portray tourists in a negative light. Tourists emerged in literature in the 1960s as wealthy, free-spending males and almost entirely as economic beings. ${ }^{65}$ They soon evolved into an entity that wreaked havoc on local communities and physical surroundings. ${ }^{66}$ This thinking has been hard to shake, and tourists are still viewed as 'shallow and gullible seekers of entertainment, banal, loud, naive and, most damning of all, uncultured. '67 This is particularly the view in heritage management contexts where they are seen as threats and “destroyers' of fragile heritage site.'68

Watson, Waterton and Smith argue that such attempts at characterisation are reductive and limits experience to consumption. ${ }^{69}$ Tourism and tourists are then investigated in correlation to market segmentation, product positioning, branding and effective communications. Culture becomes commodified, products can follow a set of guidelines, the needs of the market are then addressed and any motivation to look deeper is lost as 'the job is done. ${ }^{70}$ This approach is the result of viewing cultural tourism as a subsection of the wider tourist study and produces a shallow outcome. Watson, Waterton, and Smith, instead, advocate for considering the cultural "work" done in the act of visiting heritage site. ${ }^{71}$ They suggest an open platform and critical engagement about 'who and what a tourist $i$, and what tourism and tourists $d o$, and to consider critically what is created when tourists and host communities

62 Smith, The Uses of Heritage, 7.

63 Staiff, 2 (also Smith 2006, Byrne 2007, 2008; Harrison 2013).

${ }^{64}$ Laurajane Smith, Emma Waterton and Steve Watson, The Cultural Moment in Tourism, (New York: Routledge, 2012), i.

65 N.H.H. Graburn and D. Barthel-Bouchier, "Relocating the tourist," International Sociology, 16:(2001), 147-58.

${ }^{66}$ Graburn and Barthel-Bouchier, 148.

67 Smith, "The cultural 'work' of tourism," 210.

68 Smith, "The cultural 'work' of tourism," 210.

69 Smith, Waterton and Watson, 3.

70 Smith, Waterton and Watson, 4.

${ }^{71}$ Smith, Waterton and Watson, 8. 
interact and collide. ${ }^{72}$ Within this is the importance of recognising the agency of tourists. They are not just passive consumers, 'they create and recreate affective individual and collective cultural meaning. ${ }^{73}$

Falk and Dierking examine visitor experience regarding the personal, sociocultural, and physical contexts of the museum and its visitors. All museum visits 'can be understood as occurring at the intersections of these three contexts. ${ }^{.74}$ Although much of their discussion is heavily education-centred and museum-specific, it holds relevance for heritage sites. The personal context is what visitors bring with them; it represents each visitor's unique context, a diversity of experiences and knowledge, interests, attitudes, motivations and modes of learning. ${ }^{75}$ Socioculturally, both visitors and museum professionals, are each 'born into' and develop 'a cultural milieu of shared beliefs, customs, values, language, and thought processes. ${ }^{976}$ This is also affected by social interaction; whether visitors are within a group or on their own; those that make up the group dynamic; and, those that people come into contact with while there. Finally, the physical context refers to the setting of the museum, including the architecture or building space, the objects within it, exhibitions and interpretive material. The physical context influences how visitors move through it which affects both what they observe and what they remember from their visit. ${ }^{77}$ Added to this model is a fourth aspect: time. A museum visit cannot be viewed simply as a 'snapshot' or a single moment in time, it must take into consideration 'an individual across a larger swath of his life, and the museum within the larger context of the community and society. ${ }^{78}$

Falk and Dierking also suggest a focus on a needs-based understanding of visitor behaviour. Although not a typical way to think about human behaviour we all 'regularly select settings to visit that afford us specific opportunities to satisfy specific needs. ${ }^{79}$ People visit museums to 'satisfy specific, often highly personal and/or sociocultural needs. ${ }^{90}$ Alongside satisfying these certain needs, visitors also hold certain expectations. Evidently, when these expectations are

\footnotetext{
72 Smith, Waterton and Watson, 13.

73 Smith, Waterton and Watson, 13.

74 Falk and Dierking, Museum Experience Revisited, 26.

75 Falk and Dierking, Museum Experience Revisited, 27.

76 Falk and Dierking, Museum Experience Revisited, 27.

77 Falk and Dierking, Museum Experience Revisited, 28.

78 Falk and Dierking, Museum Experience Revisited, 28.

${ }^{79}$ Falk and Dierking, Museum Experience Revisited, 31.

80 Falk and Dierking, Museum Experience Revisited, 33.
} 
not meet, 'museums are not popular.' ${ }^{11}$ Even though visitors operate at the intersections of different physical, sociocultural, and personal contexts there are 'a series of often unspoken and even potentially unconscious, but nonetheless clear, expectations. ${ }^{92}$

During a survey undertaken in Bethlehem to understand what people seek when they visit historic sites and museums, Cameron and Gatewood accidentally came across what they termed 'numen-seeking.' ${ }^{93}$ Through the visitor surveys, they found that people sought or desired personal experience. They noted that verbatim remarks went beyond just learning about or enjoying historical sites and used 'highly affective language.' ${ }^{4}$ Borrowing from Religious Studies, the authors use the term "numen" to describe "the essential quality of visitors' personal experiences.' ${ }^{95}$ In its Latin etymology, it means 'a nod or beckoning from the gods, an invitation to make contact with the sacred.' ${ }^{86}$ Conceptually the authors attribute three aspects to numen: deep engagement; empathy; and, awe or reverence.' ${ }^{87}$

Smith found a similar phenomenon during visitor interviews conducted across a range of heritage experience. ${ }^{88}$ Her questionnaires purposely omitted any direct reference to learning or its synonyms, and although visitors talked about learning, several other experiences were discussed. What emerged from the data was the idea that visitors may go to museums and heritage sites 'to seek reinforcement or legitimisation of self.' ${ }^{99}$ She found that visitor experience 'went well beyond the messages embedded in the exhibitions by curatorial staff,' and there was a 'critical visitor interplay' as visitors were making critical and political observations. While doing so 'they are often remembering and reinforcing their own political

\footnotetext{
${ }^{81}$ Hooper-Greenhill, 6.

82 Falk and Dierking, Museum Experience Revisited, 32.

83 Cameron and Gatewood, 236.

${ }^{84}$ Cameron and Gatewood, 239.

85 Cameron and Gatewood, 239.

${ }^{86}$ Cameron and Gatewood, 239.

87 They define deep engagement as 'a transcendent experience in which one often loses the sense of time passing'; empathy as 'a strongly affective experience in which the individual tries to conjure the thoughts, feelings, and experiences, including hardships and suffering, of those who lived at an earlier time'; and, awe or reverence as 'an experience of being in the presence of something holy or of spiritual communion with something or someone.' Cameron and Gatewood, 241-242.

88 She draws on three sources of data: interviews with visitors to exhibitions marking the 1807 bicentenary of Britain's abolition of the slave trade; street interviews undertaken in the same year targeting non-museum visitors experience of the bicentennial; and thirdly, interviews collected from a range of different genres of museums in England, Australia, and the United States, Smith, "Theorising Museum and Heritage Visiting," in The International Handbooks of Museum Practice, Conal McCarthy (ed.), (New York: John Wiley \& Sons, Ltd., 2015).

89 Smith, "Theorising Museum and Heritage Visiting," 475.
} 
and cultural values, values that they possessed before entering the exhibitions. ${ }^{90}$ Visitor experience, then, is a form of cultural production involving a range of activities. Smith's study reveals a different level of visitor experience which is not passive but shows visitors 'engaged in the performance of meaning- and heritage-making. ${ }^{91}$

\subsubsection{Visitor Studies}

The importance and value of visitor studies can be seen in the above studies and is outlined by authors such as Lee Davidson. Visitor research is not limited to evaluation surveys at the completion of a project and as Davidson explains: visitor studies as performed today is 'a broad field encompassing various forms of research and evaluation relating to museums and their existing or potential visitors, and the wider communities they serve. ${ }^{92}$ Although the discussion is museum-centered the principles are applicable for heritage sites, especially regarding the areas typically studied by visitor research such as: 'visitation rates and patterns; visitor demographics and psychographics (including leisure habits and learning strategies); visitor motivations, behaviour, experiences, and perceptions; non-visitors' perceptions and barriers to visiting; broader community needs and perceptions of value; and exhibition and program evaluation. ${ }^{93}$ The desire to provide the best experiences for visitors and the need to measure performance means visitor research is an immeasurably valuable tool for museums and heritage sites.

Significant to this discussion is Davidson's suggested potential for visitor studies to bridge the gap between theory and practice. ${ }^{94}$ Rather than relying on suspicion and hunches, evaluation in the form of visitor studies is critical as a means of obtaining performance feedback, as justification to continue or modify existing programmes, and as a basis for the implementation of new ones. ${ }^{95}$ This is particularly relevant for the use of digital applications in heritage interpretation where few studies have been conducted: results may, indeed, reinforce or justify their current use in heritage management, or, they may reveal a need to

\footnotetext{
90 Smith, "Theorising Museum and Heritage Visiting," 478.

91 Smith, "Theorising Museum and Heritage Visiting," 478.

92 Lee Davidson, "Visitor Studies: Toward a Culture of Reflective Practice and Critical Museology for the Visitor-Centered Museum," in The International Handbooks of Museum Practice, ed. Conal McCarthy, (New York: John Wiley \& Sons, Ltd., 2015), 503.

93 Davidson, 507.

94 Davidson, 520.

95 G. Michael Hall and Simon McArthur, Integrated Heritage Management: Principles and Practice (London: The Stationary Office, 1998), 252.
} 
reconsider how they might be used as an effective interpretation tool. Without empirical study, we are in the dark.

\subsubsection{Conclusions}

The literature in this review has revealed that heritage is a subjective cultural and political negotiation of personal, sociocultural, and physical contexts. The very act of visiting a heritage site is a complex and dynamic practice. It is complicated further by its increasing popularity in the tourism industry and the concerns for the commercialisation of heritage to cover operational costs and increase revenue. Through competition with other leisure activities and the increasing prominence of digital technology in our everyday lives, heritage managers have readily adopted digital technology as a technique for interpretation and presentation of heritage, despite a lack of empirical evaluation. The smattering of studies on museums and digital interpretation primarily look at social media and education platforms in the museum, but very few look outside of the museum to heritage sites.

In a country like New Zealand where the tourism industry plays a prominent role, it seems increasingly crucial that we understand how these heritage sites are being perceived and experienced by visitors, both locally and internationally. Evaluation of interpretation is needed to ensure what is being offered isn't simply a passive, one-way transfer of information but enables visitors to experience active cultural engagement with a heritage site. From the literature, there appears a clear need to examine the perceived potential of digital apps as effective interpretation tools against the experience of visitors who use them. There is a need for empirical study which brings together visitor experience and institutional perspectives. By investigating what kind of visitor experience mobile apps provide, heritage managers will be better informed in making decisions regarding the interpretation and presentation of heritage sites. 


\subsection{RESEARCH DESIGN}

\subsection{Background}

This chapter outlines the research questions, aims, and methodology that have directed this investigation. As discussed in the previous chapter, there have been few New Zealand museum studies or heritage academics who have written about digital interpretation techniques in a New Zealand context and even fewer regarding mobile apps at heritage sites. The research questions have been designed to provide an exploratory study for further investigation in the heritage sector. It includes the perspectives of both heritage managers' experience of developing a mobile application and the visitor's experience of that same application on site, whereby, a deeper, richer understanding of mobile apps as an interpretation tool can be gained.

\subsection{Research Questions}

The aim of this study is to investigate the relationship between mobile technology and visitor experience at heritage sites. The study looks at two current heritage sector mobile applications and investigates the potential advantages and disadvantages of using apps by exploring the development process and institutional perspective of developing a mobile application and then comparing it to the actual visitors' experience of that mobile app.

\section{Primary Question:}

What kind of visitor experience do mobile applications provide at heritage sites in Aotearoa New Zealand?

\section{Secondary Questions:}

In what ways do mobile apps enhance (or diminish) visitor experience at heritage sites?

What challenges do heritage professionals face in implementing mobile application interpretation?

How do current technology outputs align with heritage interpretation requirements?

\subsection{Methodology}

This research project uses an interpretivist paradigm. In general, this paradigm follows two beliefs about the nature of knowing and reality: firstly, relativist ontology assumes that all we know is constructed through meanings and understandings that are developed socially and experientially; secondly, subjectivist epistemology assumes that we cannot separate ourselves 
from what we know, therefore, the researcher and the object of research are linked in such a way that who we are and how we perceive the world is a primary part of how we understand ourselves, others and the world. ${ }^{1}$ The interpretivist paradigm acknowledges that the researchers own values are inherent in all phases of the research process, and truth must be negotiated through dialogue. ${ }^{2}$ Encouraging dialogue to develop between researcher and respondents is critical, it is through the dialectical process that a more informed and sophisticated understanding of the social world can be created.

The role of the researcher, then, is critical to this research project. Bowen outlines the stance of the researcher in relation to a qualitative inquiry where 'the investigator is the primary instrument of data collection and analysis; the researcher/analyst relies on skills as well as intuition and filters data through an interpretive lens. ${ }^{\prime 3}$ Challenges arise in attempting to understand and interpret the range of perspectives and complexities in the case. Reflexivity is a key tool in mitigating the negative effects that can occur with an interpretivist paradigm. Recognising the need for reflexivity in social research can be found throughout the literature on qualitative research. ${ }^{4}$ Mason argues for 'active reflexivity,' which involves 'critical selfscrutiny by the researcher... the researcher should constantly take stock of their actions and their role in the research process, and subject these to the same critical scrutiny as the rest of their data. ${ }^{5}$ Reflexivity is a key tool applicable at every level of the research process, from data collection and analysis, through to the "write up" and presentation. ${ }^{6}$ Elliott advocates 'research which makes clear the perspective of the author and describes the practicalities of how the research has been conducted.'7 This ensures that full disclosure is given to all relevant parties including the researcher themselves.

The strategy of inquiry in this qualitative project was a case study approach. A case study approach allows for a detailed contextual analysis of the research question and enables a deep

\footnotetext{
${ }^{1}$ M. J. Angen, "Evaluating interpretive inquiry: Reviewing the validity debate and opening the dialogue" in Qualitative Health Research, 10.3 (2000): 378-395.

2 Peta Darke, Graeme Shanks, and Marianne Broadbent, "Successfully completing case study research: combining rigor, relevance and pragmatism," Info Systems f, 8 (1998): 273-289.

${ }^{3}$ Glenn A. Bowen, "Document Analysis as a Qualitative Research Method," Qualitative Research Fournal, 9.2 (2009): 37.

${ }^{4}$ Norman Blaikie, Designing Social Research: The Logic of Anticipation, second edition, (Cambridge: Polity Press, 2009), 53.

5 Mason, 2002, 7, qtd in Blaikie, 53.

${ }^{6} \mathrm{~J}$. Elliott, "The researcher as narrator: reflexivity in qualitative and quantitative research," in Using Narrative in Social Research, J. Elliott, (London; Thousand Oaks; New Delhi: Sage, 2005), 32.

7 Elliott, 32.
} 
understanding of the phenomena under investigation. Yin suggests that case study inquiry contends with the 'technically distinctive situation in which there will be many more variables of interest than data points,' resulting in multiple sources of evidence and a need to triangulate the data. ${ }^{8}$ Initially, I thought using a single case would be the best way to focus the research, to explore the nature of the particular social phenomenon that occurs with mobile apps as a tool of interpretation of heritage sites. However, following the mobile application appraisal, there arose two approaches towards mobile development that should be investigated: using a pre-built platform; compared to, developing an app from scratch.

One challenge of employing an ethnographic, specifically case study, approach is reconciling the need to produce findings that have a wider application beyond the specific case study. ${ }^{9}$ The nature of case studies and one of their advantages is the "potential to deal with subtleties and intricacies of complex social situations,' however, scepticism about the findings can arise from 'doubts about how far it is reasonable to generalise from the findings of one case.'10 Denscombe outlines several practical ways to overcome this in the project, including acknowledging and tackling the issue head-on. Limitations of the research findings should be acknowledged and a discussion of its wider relevance should also be included. Yin points out that like experiments, 'case studies are generalisable to theoretical propositions and not to populations or universes,' the goal, then, is to do a "generalising" and not a "particularising" analysis. ${ }^{11}$

There are several different types of case studies with clear distinctions between them. Bryman describes five types: the critical case; the extreme or unique case; the representative or typical case; the revelatory case; and, the longitudinal case. ${ }^{12}$ The case selection in this project was based on choosing a representative or typical case, where 'the objective is to capture the circumstances and conditions of an everyday or commonplace situation.' ${ }^{13}$ Bryman prefers to call such cases exemplifying, to avoid confusion with the notions of representativeness. ${ }^{14}$ For him,

\footnotetext{
${ }^{8}$ Robert K. Yin, Case Study Research: Design and Methods, (London: SAGE, 2009), 18.

${ }^{9}$ Martyn Denscombe, The Good Research Guide: for small-scale social research projects, fourth edition, (Maidenhead: McGrawHill/Open University Press, 2010), 85.

10 Denscombe, 60.

11 Yin, 15.

12 Alan Bryman, Social Research Methods, (Oxford: Oxford University Press, 2012), 55.

13 Yin, 48.

14 Bryman, 56.
} 
'exemplification implies that cases are often chosen not because either they are extreme or unusual in some way but because either they epitomise a broader category of cases or they will provide a suitable context for certain research questions to be answered.'15

\subsection{Mobile Application Appraisal \& Case Study Selection}

To establish context for the project an appraisal of currently available heritage-focused mobile apps was conducted. This was defined as mobile apps which explore heritage themes and are site specific. Following the New Zealand Framework for Cultural Statistics "heritage site" is defined as:

Buildings, structures, and areas of land, including archaeological sites, notable for their importance in New Zealand's history, and for their historic, cultural, spiritual, aesthetic, social or architectural value. They may be privately or publicly owned and are not necessarily open to the public. ${ }^{16}$

Each mobile app was read as "text" and then described as field notes following criteria: who the app is produced by/for; the platform or designer; device availability (i.e. Android or Apple); description of the app; format; social media capabilities; content and media, including text, images, external links, video, audio, maps; available languages; and, cost. I gathered first-hand information by downloading and exploring the mobile apps on my personal smartphone but not in-situ at the heritage sites. From this, a summary of each mobile app was created and helped inform the selection of the case studies. The following mobile applications were investigated:

- Heritage NZ Suite of Tours: Path to Nationhood Suite of Northland Tours E् Waikato War Driving app - Heritage NZ

- Denniston Rose Literary Trail

- Walk Auckland - Auckland Council and IPENZ

- STQRY - Wellington stories, i.e. Somes Matiu, Waterfront

- Roadside Stories - Ministry for Culture \& Heritage

- Ngā Tapuwae Gallipoli - Ministry for Culture \& Heritage

\footnotetext{
15 Bryman, 56.

${ }^{16}$ For example: memorial, heritage walk, pa site, historic house or gardens, archaeological sites, sites of significance to Māori, including wāhi tapu, architectural complex, standing structures.
} 
- IPENZ Wellington Heritage Walking Tour, part of the IPENZ Engineering Tours - IPENZ \& Engineering Heritage NZ

- High Street Stories: the life and times of Christchurch's High Street Precinct - Heritage NZ

- The 1846 War in Wellington: a guide to sites - Ministry for Culture and Heritage

- Welly Walks - Wellington City Council

- Reefton Power House Walk - Reefton Powerhouse Trust

There are three main types of apps available: native, hybrid, and web. Native apps are those that are generally built from scratch. It is downloaded from an app store, and it sits within the smartphone applications. It has full access to the device's hardware, including the camera, microphone, compass, and swipe gestures. They are the fastest, most reliable and most responsive for users but also generally the most expensive and complex to build. ${ }^{17}$ The two main phone platforms available, iOS and Android, are built using different programming languages and therefore a separate version of the app needs to be built and maintained for each platform, essentially doubling the workload. ${ }^{18}$ Developers can choose to produce the app for one platform and exclude the other.

Hybrid apps are built using a web programming language that is compatible with both operating systems and then native code is essentially wrapped around the app so it can have access to the specific hardware of the phone platform. ${ }^{19}$ Therefore, only a portion of the native code needs to be re-written for each different device. Hybrid apps are not as fast or as responsive as native apps as they are dependent on plugins, slowed by browser speed and can be affected by changes to operating systems. ${ }^{20}$ Then there are Web apps, or mobile-optimized websites, which are the mobile version of a website. These load within your mobile browser like Safari or Ghrome rather than needing to install an app. It allows you to view a web page

\footnotetext{
17 Charlie Harman, "Native Vs. Hybrid - Which should you choose?” Calvium, published 6 November 2014, https://calvium.com/native-vs-hybrid-choose/

$18 \mathrm{iOS}$ and Android hold the largest market share, however, there are other platforms such as Windows Microsoft mobile phone platform and Blackberry.

19 Harmen, 2014.

20 Tom Melamed, "The blagger's guide to talking about apps with authority," Calvium, published 16 February 2016 , https:/ / calvium.com/the-blaggers-guide-to-talking-about-apps-with-authority/
} 
using your smartphone and the content will respond to the smaller screen format and navigation. These can mean drawing on the fact you may already have a website developed. ${ }^{21}$

Another option is to use a pre-built mobile application with specific features that content is uploaded to. An example of these in New Zealand are STQRY and My Tours where the app is built in a web browser following the templates, then hosted by either STQRY or MyTours. ${ }^{22}$ The application is limited by what features the company chooses to provide. Both platforms require a setup fee and then an annual subscription to keep the app running. Any updates required are handled in-house by the platform, therefore running and maintenance costs are all part of the subscription. Content can easily be added or adjusted without having to write new code.

Of the 11 apps reviewed for this summary, four used similar versions of the My Tour Apps platform and two used older versions of the platform. Companies using the STQR platform were grouped under one entry, as the features and layout did not alter between them. Four of the apps were native apps, designed by contracted design companies and therefore had individual layouts and design features. Several of the institutions had mobile optimised websites in addition to the mobile applications, these were Heritage New Zealand, Ministry for Culture and Heritage, and Wellington City Council.

The apps used a variety of media as interpretation devices, this included: audio, video, and, images. ${ }^{23}$ One app, High Street Tours, used the feature of augmented reality to overlay the historic version of High Street over the scene you see at the time of visiting, this was the only app to use an AR or VR feature. Most apps (7 out of 11) were connected to social media and allowed "checking in" with social media in-app.

\footnotetext{
${ }^{21}$ Mat Hollingsworth, "Not all apps are created equal: Mobile apps vs mobile-optimsed web apps," inoutput, publised 24 February 2016, http://inoutput.io/articles/development/understanding-the-difference-between-mobile-apps-and-mobileoptimised-web-apps

22 These can be found at https://www.stqry.com/ and https://www.mytoursapp.com/.

23 Images included contemporary photographs, historical images, maps, infographics, illustrations, newspaper articles, etc.
} 
All the apps trialled were free to download, with only one tour within the app charging a fee. $\left.{ }^{24}\right)$. One app, Nelson Walking Audio Tour, based on the My Tours App platform was noted but not reviewed as it charged for download. All bar one app was available on both Apple and Android devices; High Street Stories was Android compatible only. All the apps, except for those on the STQRY platform and High Street Stories, followed a tour format, taking visitors through a succession of locations.

Following the information gathered during the appraisal of current mobile apps, two case studies were selected to explore further. These were: High Street Stories: the life and times of Christchurch's High Street Precinct and the Wellington Heritage Walking Tour as part of the IPENZ Engineering Tours. Selection of these case studies required careful consideration and several criteria: selecting information-rich cases for in-depth study; referring to the purpose of the study to ensure appropriateness; and, feasibility including the size of the study and resources. From the heritage app overview, there arose two types of mobile app: the first is a purposedesigned platform for the project, commissioned by an institution and created by a design company; the second design is using a basic mobile application template that users subscribe to and upload content to the platform. These two design types can be considered typical or exemplifying instances and were selected to compare these two avenues available to heritage institutions seeking to create mobile apps.

Selection of the case studies was also influenced by several practical considerations, specifically, what Denscombe calls 'a matter of convenience,' and 'intrinsically interesting. ${ }^{25}$ For convenience of location one heritage site is in Wellington where the researcher is based and the other in Christchurch where the researcher is familiar. Secondly, Wellington Heritage Walking Tour is intrinsically interesting as it uses all available media, bar audio, on the $M y$ Tours Apps platform and High Street Stories because it uses Augmented Reality, a feature not used in any other of the mobile apps reviewed. Both mobile apps were commissioned by an institution and therefore provided the opportunity to conduct interviews with those responsible for commissioning the app and to explore the decision to choose either a predesigned platform or a purpose-designed one.

\footnotetext{
${ }^{24}$ Auckland's Original Shoreline Walk in the Walk Auckland app charged \$1.49.

25 Denscombe, 58-59.
} 


\subsection{Methods}

Following the selection of the case studies the research was conducted in two parts. The first stage of the project involved interviews with heritage professionals and digital designers relevant to the development of the case studies, conducted via email. Part two involved questionnaires and semi-structured interviews with recruited participants who visited the selected heritage sites using the mobile applications.

\section{Email Interviews}

To establish context and a deeper understanding of the mobile applications being investigated, interviews were conducted with a spokesperson for the heritage institution and from the design company for each case study. For High Street Stories: the life and times of Christchurch's High Street Precinct this was with Heritage New Zealand's Area Coordinator for the Canterbury and West Coast regions, Zoe Roland, who acted as project manager and Gun Lee, a technical director of mobile app development at HIT Lab. For Wellington Heritage Walking Tour as part of the IPENZ Engineering Tours interviews were conducted with the IPENZ Heritage Advisor, Karen Astwood, who was tasked with project managing the development of the app and the creator and director of My Tours App, Glen Barnes. These interviews were conducted via email with a set of prepared questions sent to each participant; one set specifically designed for the heritage professionals and one relevant to the digital developers. There was some flexibility and conversation allowed when certain points required expanding on. By conducting the interview via email, it reduced transcribing time and allowed the participants to review answers as they went.

\section{Visitor Questionnaire and Interview}

The second part of the project was to examine the visitor perspective and their experience of using the mobile apps in context. Onsite recruitment would have been extremely challenging for these case studies. The sites and locations that these apps covered are widespread, and it would have been difficult to identify app users purely through observation. The download figures as seen on the App Store and Google Play were also not high enough to warrant onsite recruitment and data gathering. In an ideal world, with infinite resources, this visitor questionnaire would target both heritage app users and non-users to compare the experience of the heritage site by both types of visitor. However, given the size and scope of this 
investigation, only visitors using the apps were interviewed. To make this a more manageable task, participants were recruited to visit the site, answer a preliminary questionnaire and then participate in an interview following their visit.

Sampling for the study was exploratory to generate insights and information. ${ }^{26}$ This type of sampling does not provide a representative cross-section of the population or necessarily typical examples, which was considered when analysing the data gathered. The method used was snowball sampling, a form of convenience sampling where the researcher makes initial contact with a small group of people relevant to the topic and then uses them to make contacts with others. ${ }^{27}$ Recruitment for participation used two methods: making use of personal contacts and electronic communication. A call for participation was advertised via social media (Facebook and Twitter) with a link to the description page of the research project and the initial questionnaire. This link was then "shared" between these networks to reach a wider range of people. Word-of-mouth for recruitment was used to take advantage of the researcher's networks in Wellington and Christchurch. Self-selection sampling was the type of non-probability sampling technique used as participants chose to take part in the research on their own accord. The disadvantage of this method is the likelihood of selfselection bias, where the decision to participate may reflect an inherent bias in the character or personality of the participants. This was evident anecdotally, through some of the comments left on the shared Facebook pages, where people suggested the project was not for them as they were not digitally literate or confident.

A preliminary self-complete questionnaire was administered via Qualtrics, an online survey tool for data collection and analysis, to gather basic demographic information and the participant's exposure to heritage interpretation, including both traditional and digital. Several authors have found evidence which suggests the quality of data gathered through web-based means does not significantly differ to that obtained through more conventional means. ${ }^{28}$ The advantage of using a questionnaire is that it allowed responses from participants in different locations. ${ }^{29}$ There are three key benefits to using a questionnaire in this project: the focus on empirical data; the ability to collect both qualitative and quantitative data; and,

\footnotetext{
${ }^{26}$ Denscombe, 24.

27 Bryman, 184.

28 Cited in Denscombe, 14. McCabe (2004), Denscombe (2006, 2008, 2009), Lozar Manfreda et al. (2008)

29 Denscombe, 156.
} 
the ability to collect data efficiently and relatively inexpensively. ${ }^{30}$ The preliminary questionnaire contained a mixture of open and closed questions, but the second interview was used to gather more in-depth and complex "feelings" based answers.

Following the participants' visit to the heritage site using the mobile app one-to-one, semistructured interviews were conducted. These were either over the phone or in person. To begin the interview, they were asked to tell the interviewer about their experience using the app from when they first downloaded it. Prompts were used to keep the discussion flowing, but the participants primarily led it. This method was used to gain insight into people's opinions, feelings, emotions, and experiences relating to the topic. Semi-structured interviews gave flexibility to the data collection, allowing fluidity regarding the order in which subjects are considered, allowing the interviewee to 'develop ideas and speak more widely' while maintaining a clear set of issues to be discussed. ${ }^{31}$ This helped to keep the interview on-topic while not being overly restrictive.

\section{Analysis}

The analysis of qualitative data can be undertaken in several ways reflecting the diverse nature of the data itself. Rather than analysis taking place at one fixed time, it tends to be an evolving process where data collection and analysis occurs simultaneously, each informing the other. ${ }^{32}$ To give structure to the process a thematic analysis of the data was used. Thematic analysis is particularly suited to answering questions related to people's experience, or people's views and perceptions. It involves the search for "themes" where analysis is based on a matrix for ordering data, and an index created of central themes and sub-themes. ${ }^{33}$ There were several key steps involved in the process of thematic analysis. Firstly, familiarisation with the data required reading and re-reading the data to become familiar with the content. Next, the coding phase included generating succinct labels that identify broader patterns of meaning or potential themes. The data was then collated according to its relevance to each possible theme and a process of reviewing the themes to check them against the dataset. Themes were then refined, which meant they could be combined, split, or discarded. The

\footnotetext{
30 Denscombe, 49.

31 Denscombe, 175.

32 Denscombe, 272.

33 Bryman, 554.
} 
final stage was writing up which involved weaving together the narrative of the data and contextualising the analysis by referencing back to the literature.

\section{Limitations of the Research}

The research project includes some limitations which need to be acknowledged. The IPENZ Wellington Heritage Walking Tour was taken by five participants and High Street Stories by four. This was lower than the initial target of 10 participants for each heritage site, and the project could benefit from a larger sample size. However, the information gathered was intended to be qualitative rather than quantitative, and there was enough data collected to provide a platform for further study and act as an exploratory study. There was also a high rate of participants who looked at the survey page but did not complete the questionnaire. This may reflect an issue with the wording, description or presentation of the survey that some people found off-putting. Some potential participants may have considered the project to be too much of a commitment, having to visit the site physically and participate in an interview. However, data was not collected from those who did not complete the survey, so this can only be speculated.

Although research suggests that data collected using online techniques does not differ from more traditional approaches the project could have benefitted from more physical recruitment, rather than using a primarily online methodology. This could have been achieved by contacting i-SITE and visitor centres, local backpackers, hotels, and universities. The survey was only available online and not in a physical form at the heritage locations, which would have reduced the pool of possible recruits and meant a skewed population representation. However, as the project is focused on digital technology, this could be considered acceptable within the scope of this as an exploratory study. 


\subsection{THE GASE STUDIES}

This chapter gives a brief history and introduction to the two heritage mobile apps, including background to their development, the institutions involved and a description of the app itself. The case study histories have been compiled using documents and data collected during the interviews with professionals. Following this, the professional perspectives of designing and implementing the mobile applications at the two heritage sites are presented and discussed.

\subsection{High Street Stories}

\subsubsection{Background}

The Canterbury earthquake on the $22^{\text {nd }}$ of February 2011 drastically changed the urban landscape of Christchurch. The city centre experienced widespread destruction and High Street was irrevocably damaged. Parts of the streetscape of Edwardian and Victorian buildings and laneways, most with heritage significance, were demolished. At the time of the earthquake, Zoe Roland was working as Heritage New Zealand's Area Coordinator for the Canterbury and West Coast regions. Heritage New Zealand Pouhere Taonga (HNZ) is recognised as the leading national historic heritage agency. The role of HNZ is to maintain the New Zealand Heritage List, manage 48 nationally significant heritage properties, regulate the modification of archaeological sites, and, manage the national heritage preservation incentive fund. Their mission statement is 'To identify, protect and promote heritage.' The loss of heritage due to the Canterbury earthquakes of 2010 and 2011 features prominently on the HNZ website, with an entire section dedicated to an inventory of the buildings destroyed or demolished and a brief history regarding each.

Zoe Roland worked on all aspects of the High Street Stories project, as the director, producer, interviewer, and funding developer, among many other roles. She holds degrees in Anthropology, Theatre and Documentary and has spent a large proportion of her career working in libraries and museums. Zoe has worked as a freelance film and radio documentary maker, focusing on oral history stories ranging from the Vietnam War to Immigration. For her, the High Street Stories project was personal; she describes how the project developed in response to the aftermath of the earthquakes: 
I always loved sound-mapping projects and audio walking tours. After the massive loss of heritage buildings and this very important part of the city, I concocted this project and pitched it to HNZ. In a way, it was my idea of a love letter to the city. We lost our house in the first quake and we had other wider family traumas. I look back now and I was really in stress mode for years after. HNZ could see where I was at and as my other projects had all gone up in dust due to the EQs, HNZ were very kind and let me run with the project.

Inspired by a satellite streetscape project from before the quakes, Zoe developed the concept of geotagging stories to online maps. From this, NV Interactive developed a website, which was an online audio archive of the precinct to act as 'a permanent "collective remembrance"

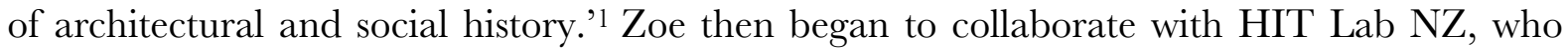
developed the mobile app for free. The project was funded by the Christchurch Earthquake Appeal, Vodafone and Internet New Zealand and supported by HIT Lab, NV Interactive, and CEISMIC. ${ }^{2}$

\subsubsection{HIT Lab}

The Human Interface Technology Laboratory New Zealand (HIT Lab NZ), created the Augmented Reality mobile application. HIT Lab, based at the University of Canterbury, is 'a human-computer interface research centre' and is a partner of the international HIT Lab US based at the University of Washington in Seattle. ${ }^{3}$ It operates as a research lab at the University, developing technical solutions with new emerging technologies such as Virtual Reality, Augmented Reality, Human-Robot Interaction, Immersive Visualization, and Applied Gaming Design. ${ }^{4}$ The driving force is to improve the user experience with technology and integrate research and education, providing students with a project-based learning environment. ${ }^{5}$ Gun Lee was a technical director of the mobile app development. He described his role at HIT Lab NZ as 'leading the research projects in mobile and wearable augmented reality applications.' The lab had used similar technology to create CityView, an app no longer available, which allowed users to see a wider view of how the city was before the earthquakes and building demolitions.

\footnotetext{
1 "High Street Stories," NV Interactive, accessed 19 April 2016, https://www.nvinteractive.com/work/high-street-stories

2 "Rising from the rubble - stories of High Street," Ministry for Culture and Heritage, updated 23 July 2015,

http://www.mch.govt.nz/news-events/news/rising-rubble-stories-high-street

${ }^{3}$ Human Interface Technology Laboratory New Zealand, accessed 23 June 2016, http://www.canterbury.ac.nz/spark/Group.aspx?groupid=122

${ }^{4}$ HIT Lab, accessed 23 June 2016, http://www.canterbury.ac.nz/spark/Group.aspx?groupid=122

${ }^{5}$ HIT Lab, accessed 23 June 2016, http://www.canterbury.ac.nz/spark/Group.aspx?groupid=122
} 


\subsubsection{The Mobile App}

The High Street Stories mobile application offers audio stories about the life and times of the area, following its history, 'as a bustling commercial centre through its decline in the 1970s and $80 \mathrm{~s}$, and later regeneration into a boutique shopping and dining area.' ${ }^{6}$ The app contains over 100 stories, histories, and anecdotes from life in the precinct from architectural heritage through to stories of the red light district. It is designed as a companion app to the High Street Stories website which contains more detailed information. Each story is geo-tagged to a building or site along the street, which is visualized on an interactive map (see Figure seven). Each stop is based on an audio clip which features interviews and oral histories as told by sources such as local business owners, the NZ Prostitutes Collective, heritage advocates, property developers, Ngāi Tūāhuriri, historians, and artists (see Figure four). There is a small amount of text accompanying each audio clip, usually a short quotation taken from the audio. A single image is used to illustrate each story. External links show that more stories and pictures are available on the website. The app arranges the stories either by list or by map. The list view can filter by theme: that is, architectural heritage, Ngāi Tahu, social history, red light district, etc. or sorted by ID, theme, person, title, or distance (see Figures two and three).

As well as a map which shows each story placed on its specific site, the app also uses an augmented reality feature. This allows users to hold up their phone to the streetscape in front of them and layer a composite image of how the street once looked with how it looks now (see Figure five). A crosshair in the centre of the screen can be made to hover over coloured dots which indicates a story and the audio will begin to play (see Figure six). The colour relates to the theme of the story. Users can pan around the street and visually see where each story is. There is no set tour or route that visitors can take, it is up to them to decide; they can pick specific sites or walk from one end of the street to the other.

High Street Stories is available free for download on Android only. The app is rated in the 500-1000 installs category on the Google Play Store. ${ }^{7}$ It was last updated 5 April 2015 and requires Android 2.3 and above.

\footnotetext{
${ }^{6}$ High Street Stories, accessed 27 April 2016, http://www.highstreetstories.co.nz/splash

7 "High Street Stories," Google Play, updated 5 April 2015,

https:// play.google.com/store/apps/details?id=com.hitlabnz.hss\&hl=en
} 


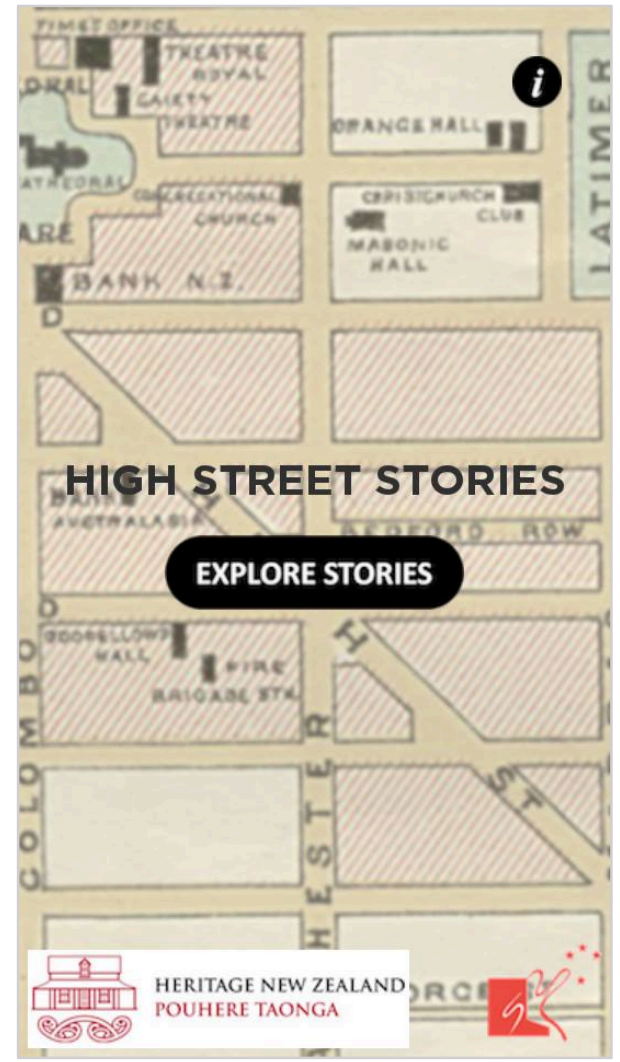

Figure one: HSS: Menu page.

\section{HIGH STREET STORIES}

\begin{tabular}{|c|c|c|c|}
\hline \multicolumn{4}{|c|}{ Search } \\
\hline 0 & $\begin{array}{l}\text { Christchurch's Red Light District } \\
\text { Anna Reed and Tracy, New Zealand Prostitutes } \\
\text { Collective } \\
\text { Distance: } 101 \mathrm{~m}\end{array}$ & 4) & \rangle \\
\hline 0 & $\begin{array}{l}\text { A world first - The Prostitution } \\
\text { Reform Act (2003) } \\
\text { Anna Reed and Tracy, New Zealand Prostitutes } \\
\text { Collective } \\
\text { Distance: } 111 \mathrm{~m}\end{array}$ & 4) & \rangle \\
\hline & $\begin{array}{l}\text { 'The Sunrise Massage Parlour' } \\
\text { Anna Reed and Tracy, New Zealand Prostitutes } \\
\text { Collective } \\
\text { Distance: } 101 \mathrm{~m}\end{array}$ & 4) & \rangle \\
\hline & $\begin{array}{l}\text { Murders and Fire Bombings } \\
\text { Anna Reed and Tracy, New Zealand Prostitutes } \\
\text { Collective } \\
\text { Distance: } 78 \mathrm{~m}\end{array}$ & 4) & \rangle \\
\hline & $\begin{array}{l}\text { Christchurch's 90s Rave Scene } \\
\text { Simon Kong } \\
\text { Distance: } 106 \mathrm{~m}\end{array}$ & 4) & \rangle \\
\hline & $\begin{array}{l}\text { Human feelings embodied in concrete, } \\
\text { mortar and stone } \\
\text { Dr. Cliff Mason, Heritage Advocate and Activist / } \\
\text { Pathologist } \\
\text { Distance: } 27 \mathrm{~m}\end{array}$ & 4) & \rangle \\
\hline & The Demolition of the Wiltshire & & \\
\hline
\end{tabular}

Figure three: Layout showing all stories.

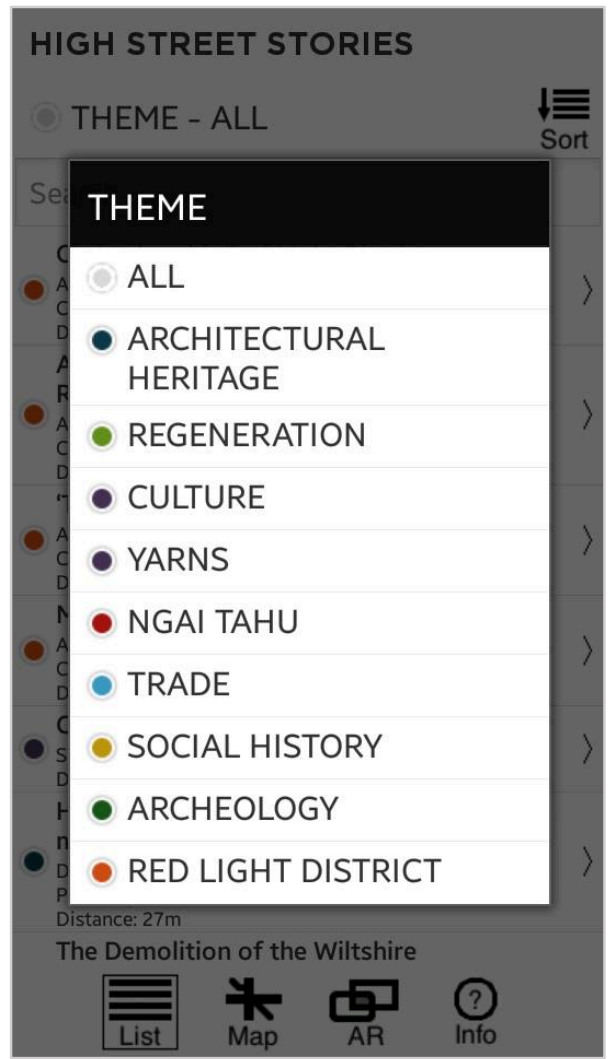

Figure two: HSS: Sorting stories by theme.

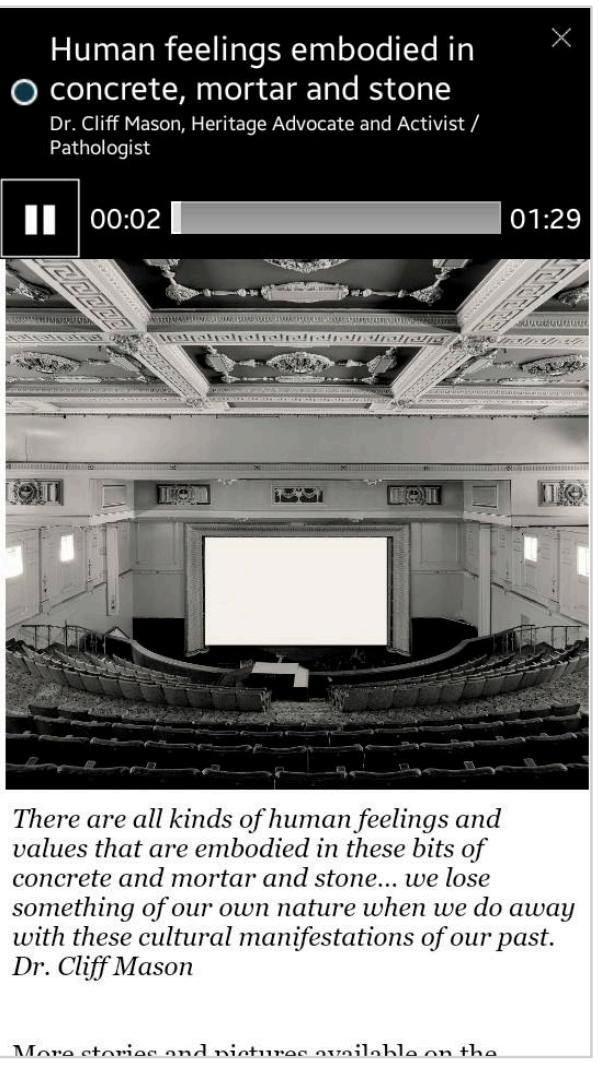

Figure four: HSS: Page layout for each story. 


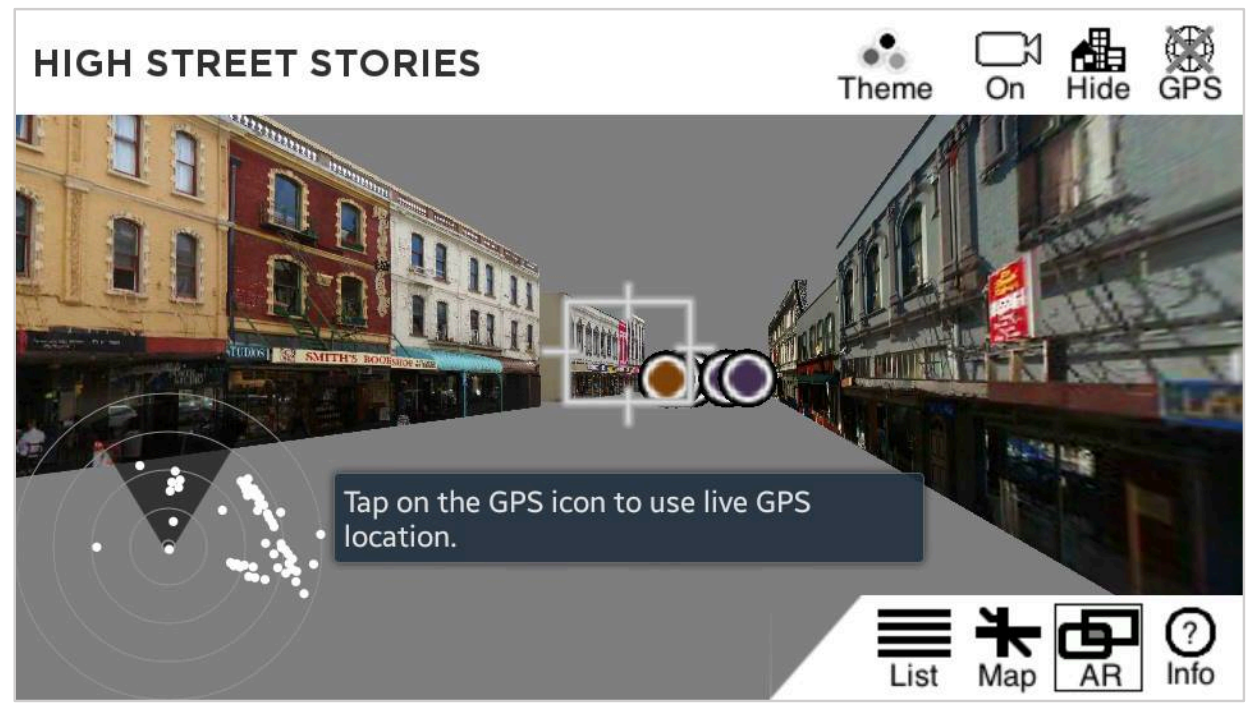

Figure five: HSS: Augmented reality feature, streetview.

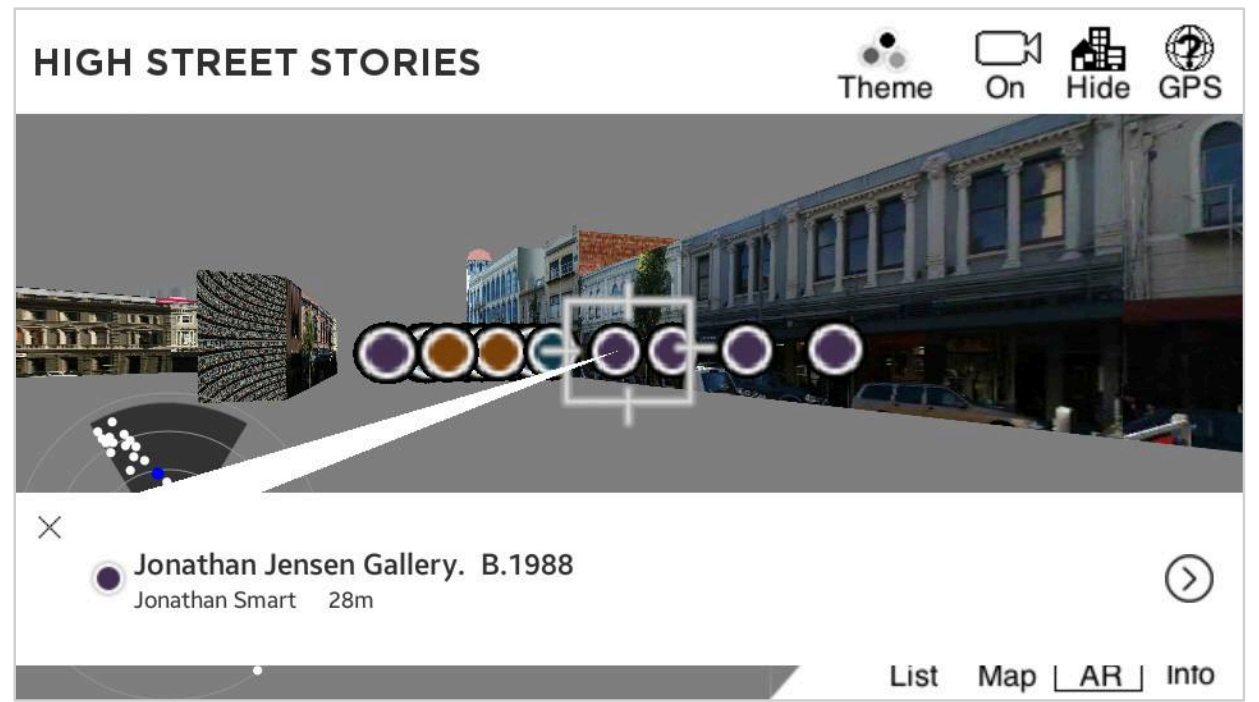

Figure six: HSS: Augmented reality feature, selecting a story.

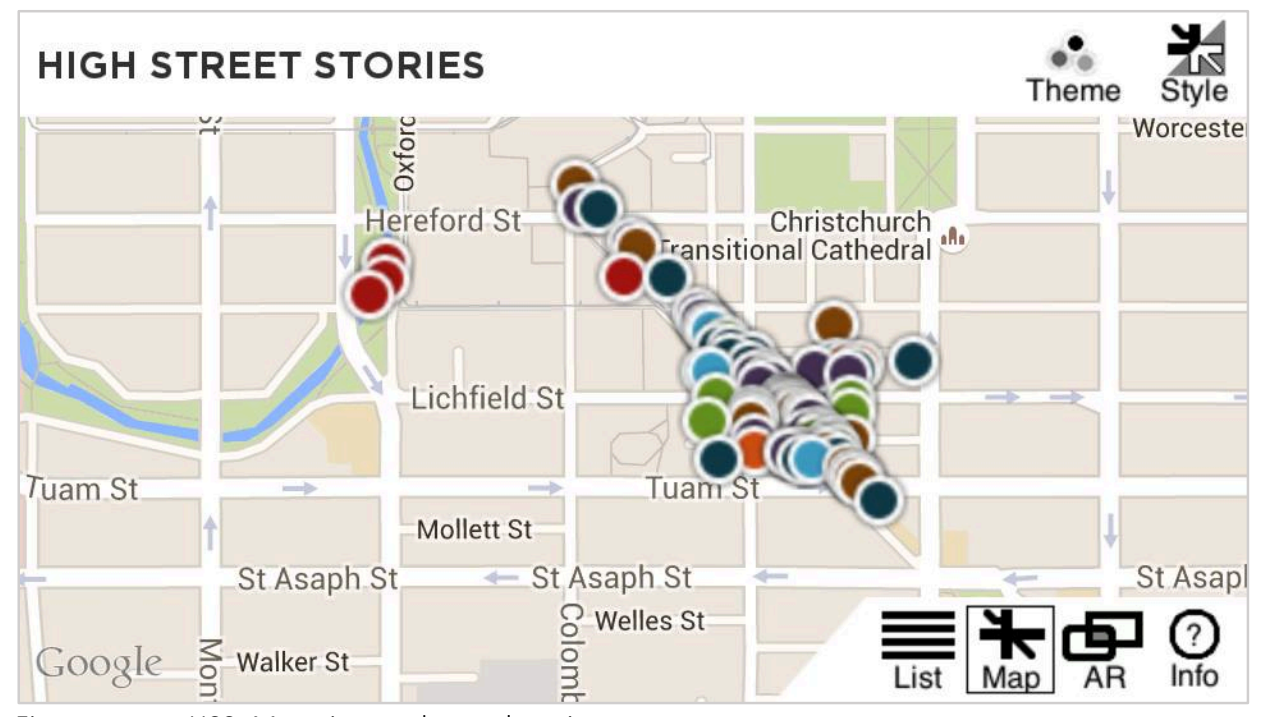

Figure seven: HSS: Map view and story locations. 


\subsection{IPENZ Engineering Tours: Wellington Heritage Walking Tour}

\subsubsection{Background}

The Institute of Professional Engineers New Zealand has a heritage branch. Their vision for engineering heritage is that 'New Zealand's engineering achievements are widely recognized and valued.' ${ }^{2}$ The key objectives for IPENZ are: identify and record engineering heritage resources; promote engineering heritage protection, preservation, and conservation; interpret and enhance understanding of engineering heritage; and, use engineering heritage to enhance public understanding of the critical role engineering plays in modern society. ${ }^{9}$ IPENZ's heritage activities are overseen by the IPENZ Engineering Heritage Board and enacted by members of regional Engineering Heritage Chapters.

Karen Astwood, in her role as Heritage Advisor, was tasked with project managing as well as providing guidance and content for the mobile application tour. After completing a Bachelor of Arts with Honours at the University of Canterbuty, Karen worked at the Centre of Contemporary Art (COCA) in Christchurch. Part of the role included writing interpretation labels and artist biographies for exhibition. She moved to Wellington to undertake study for a Master of Museum and Heritage Studies from Victoria University of Wellington. Upon completing this in 2008, Karen worked as a contract historian for the New Zealand Historic Places Trust (now HNZ) before taking on her role at IPENZ.

The project grew out of the research efforts and aims of the IPENZ Wellington Engineering Heritage Chapter, a volunteer group. The group had been collating material for a bookletbased local engineering heritage walking or driving tour. Around 2012, based on their experiences using heritage tour apps in their travels and the increasing availability of mobile products, the group turned their focus to producing a mobile application.

Switching from paper-based to a digital version of the tour had financial implications and meant the Engineering Heritage Board were consulted to explore feasibility. Karen explains that in May 2013, they 'agreed to support the creation and on-going maintenance of the

\footnotetext{
8 "Introduction," IPENZ Engineering Heritage New Zealand, accessed 27 April 2016, http://ipenz.org.nz/heritage/introduction.cfm

9 "Introduction," IPENZ Engineering Heritage New Zealand.
} 
IPENZ Engineering Tours app.' The Wellington Heritage Walking Tour was a pilot project tour within the app. As part of the proposal by the Wellington Engineering Heritage Chapter, they did research on the different options, including building a native application or using a pre-built platform. The Heritage Board decided on using the My Tours App platform.

\subsubsection{My Tours App}

My Tours is a company founded in 2009 which provides a basic digital application template compatible with a variety of media. It offers a web-based tour builder and a customisable mobile application. The idea came from founder Glen Barnes' personal experiences of visiting heritage sites:

In 2003 I was wandering around Pompeii with one of their audio guides. I had just bought one of the original iPods and started to think about how I could have the audio guide on my own device with its nice white headphones and better sound quality. I did some initial scoping work on what that would take, but it was soon apparent that the user experience of getting the content on to the device was poor.

He identified three key issues that impacted on feasibility: Firstly, you had to know that you were going to a certain location before you left home; you had to know they had an audio guide you could download; finally, it had to be downloaded and synced it to your iPod. After the launch of the iPhone and the AppStore by Apple around 2009, Barnes revisited the idea and developed the first version of the app. The platform targets 'anybody who has interpretive content to publish' which includes museums, councils, tourism boards and other heritage organisations to produce city walks, museum tours, and audio guides. The platform works by charging users a set-up fee and then annual subscription. This covers hosting, maintenance, and any updates that need to be made.

\subsubsection{The Mobile Application}

The IPENZ Engineering Tours currently offer two tours: The Auckland Waterfront Tour which is approximately 3 hours and 30 minutes, with 18 locations and is $38.4 \mathrm{MB}$ to download; the second is the Wellington Heritage Walking Tour (see Figure eight). This tour takes approximately two hours to complete, it takes visitors to 26 locations and takes $24.08 \mathrm{MB}$ to download.

Visitors start the tour at the top of the cable car; it is up to them how they arrive: they can take the cable car, drive or walk. The application features an interactive map which shows 
each stop on the tour, and if users have their data and GPS turned on, the app will also show their current location (see Figure eleven). Each site has a body of text related to the stop. For most of the stops there is a generous amount of text, generally, six to seven paragraphs which describe dates, important figures, and events (see Figure nine). High-quality images with captions are used to illustrate each segment. These are in a swipe gallery at the top of each section and include both modern day and archival/historical photographs. Some of the galleries include a video. These videos are from Archives NZ, linked to YouTube but play through the app and can be made full screen. They are long format videos, around 8-10 minutes. Each stop contains several "Further Information" links which click through to external links, i.e. Carter Observatory website, Heritage NZ listing of the Dominion Observatory. There are also several "Additional Sections" for some locations, which include biographical information about important people in the engineering narrative. There are links to social media for each stop (see Figure ten). Visitors follow the tour from the Cable Car and finish at the Electric Streetlamp, coming almost full-circle, with the bottom of the Cable Car within sight from the end.

IPENZ Engineering Tours is available on both Apple and Android and is free to download. Through the Google Play Store, the app is rated in the 100-500 downloads category and requires Android 4.0 and up. ${ }^{10}$ On the Apple AppStore it is listed as being last updated 6 May 2015, requires iOS 7.1 or later and is compatible with iPhone, iPad, and iPod touch.

10 "IPENZ Engineering Tours," Google Play, updated 23 April 2015,

https://play.google.com/store/apps/details?id=com.mytoursapp.android.app741\&hl=en 


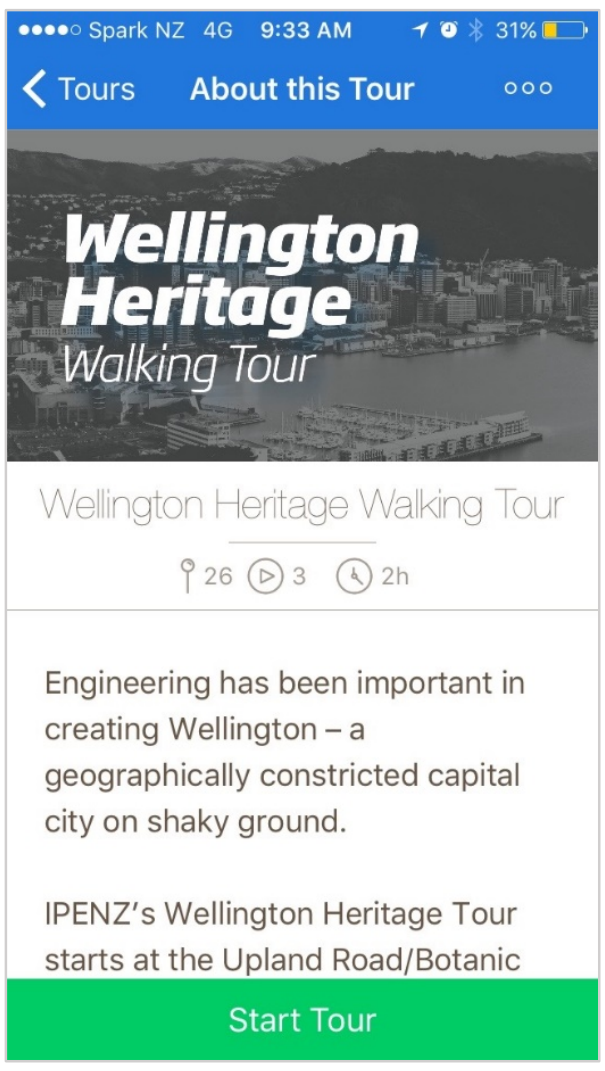

Figure eight: IPENZ: Menu page.

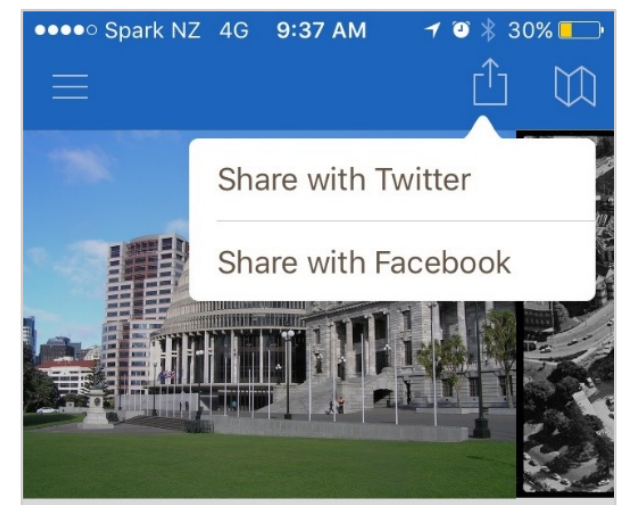

\section{Parliament}

This area has been an important place for New Zealanders since Wellington became the capital in 1865. Legislation advancing development is passed here, such as the Immigration and Public Works Act in 1870 that established the Public Works Department (Stop 6) and gave powers to take land and import

Figure ten: IPENZ: Social media options and icons for each story page.

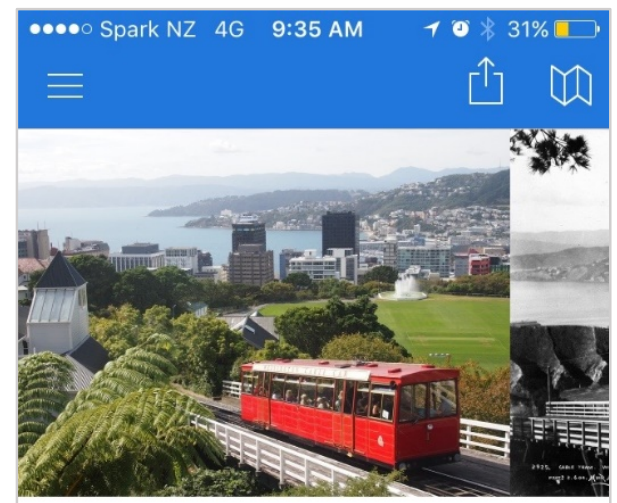

\section{Wellington Cable Car}

Wellington's Cable Car is an iconic feature of the capital and an important link to the city's Victorian transport heritage.

Despite reclamation works being carried out, by the late 19th century Wellington was crammed - so new residential suburbs were built, on the

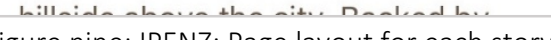
Figure nine: IPENZ: Page layout for each story.

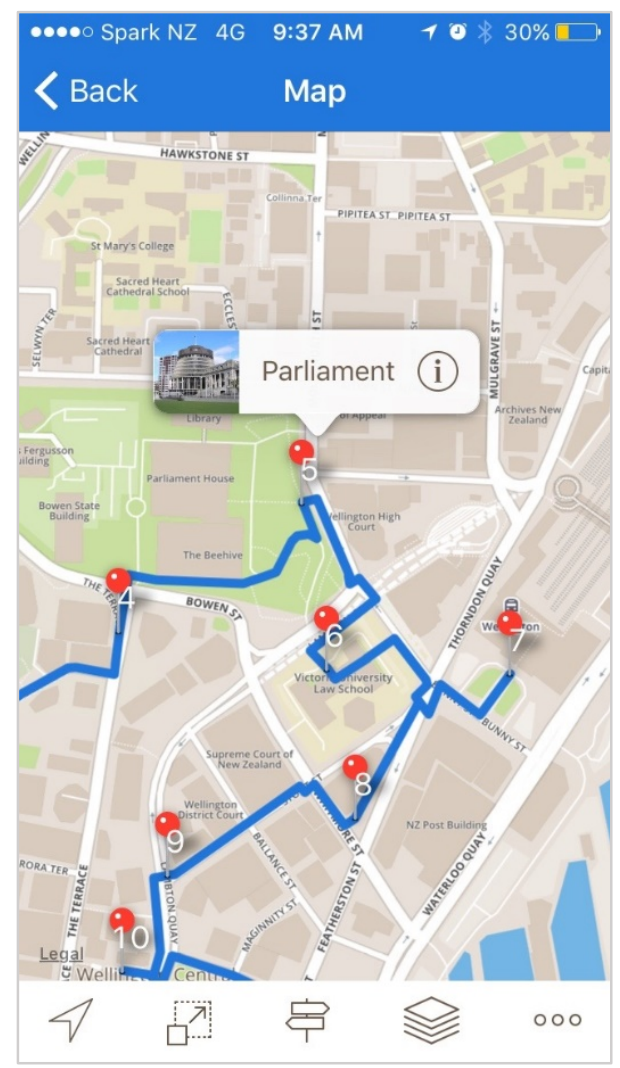

Figure eleven: IPENZ: Map view and tour layout. 


\subsection{Professional Perspectives}

The first part of this enquiry seeks to investigate the institutional perspective of designing and implementing a mobile application as an interpretation tool for heritage sites. These findings lay the basis for understanding mobile application interpretation from the institutional point of view, looking at the aims of interpretation, technology outputs, and the challenges in developing mobile interpretation for practitioners.

The heritage managers were asked to discuss the development process of the app, including the primary objectives, who the app was for and what they hoped they would get out of it. Both IPENZ and HNZ had broad goals for their mobile apps and followed the institutional strategies for guidance. For IPENZ the project was driven by its 'Engineering Heritage Strategy,' and Karen explains the specific objectives the tour contributed were: 'IPENZ's tasks of identifying and recording heritage resources, interpreting and enhancing the understanding of engineering heritage and, in doing so, enhancing public understanding of the important role engineering plays modern society.' The goal was to profile Wellington's engineering heritage and 'create a richer experience by putting engineering heritage in context.' Visitors to Wellington influenced the design of the IPENZ tour with the route developed around three key attractions in the city: Wellington Cable Car, the Parliament precinct and the Museum of New Zealand Te Papa Tongarewa. For Karen, this was 'a natural route visitors would be taking anyway, and the walking tour could add value and interest to it.' From the user perspective, the main objective for IPENZ was to produce a walking tour 'that was suitable for a broad range of ages and fitness levels.'

High Street Stories was born out of the trauma of the earthquakes, as all other projects were either put on hold or abandoned. Following HNZ's mission statement 'to identify, protect and promote heritage,' the project was an audio archive of stories disseminated digitally. Zoe describes the HSS app as being 'for anybody who wanted to use it.' At a more specific level, Zoe wanted the app to be 'user-friendly,' and for the stories to be geo-tagged to the specific buildings while keeping the audio as 'shorter sound bytes' compared to the website. Zoe talked about "an immersive experience" rather than a particular learning driver. The subject matter and circumstances of the development of the app were grounded in more emotive 
characteristics, as Zoe explains: 'The first time I used it I cried as it was an incredibly powerful tool for transporting you back in time to see and hear what was totally gone.'

Several authors examined in the literature review stressed the importance of carrying out visitor studies to evaluate all stages of a project. While neither of the institutions conducted indepth or formal visitor studies, both went through pilot-testing and informal reviews. During the development stages, the tour was tested by a group of IPENZ volunteers and staff who provided anecdotal evidence that 'users were happy with the level of information and the format of the tour.' IPENZ has used the analytics tools offered by Google and Apple regarding user downloads and updates but has not conducted audience surveys since the launch of the app, however, Karen commented that undertaking this 'would be a good follow-up step.' As part of a public program initiative following the release of the app, Zoe and Gun took several tours and gathered anecdotal evidence from these encounters with visitors. They found that a lot of older people turned up to the tours and Zoe and Gun talked them through how the technology worked. On the other hand, the digital companies carry out testing as part of the development process. In developing CityViewAR, the precursor technology to HSS, HIT Lab conducted practical user-studies of AR technology for the development in December 2011. ${ }^{11}$ Although this study was not heritage focused the results showed that there was scope for applications like that to have more emphasis on heritage and curated tours.

One aim of the research was to investigate the challenges faced by heritage professionals when developing mobile interpretation and offer insights that could be used in the development process. From the interview with Karen, this emerged as an important endeavor. She writes:

The main challenge was locating guidance on how to create a heritage tour. Early in the pilot project process I searched for available resources, including conference papers and 'how-to' guides, but found no substantive guidance or a step-by-step process which IPENZ could adapt to its own needs to create an effective and user-friendly app tour. Therefore, in the initial stage of the project, there was a considerable amount of thinking around how to balance user experience with IPENZ's goals.

11 Gun A. Lee, Andreas Dünser, Seungwon Kim, Mark Billinghurst, "CityViewAR: A Mobile Outdoor AR Application for City Visualisation,” Human Interface Technology Laboratory Report, (Christchurch: University of Canterbury, 2012), 4. 
Karen drew on her expertise gained during her Masters of Museum and Heritage Studies and work experience, which included different types of interpretation methods, to write a set of guidelines for writing app tours. This document was specific to IPENZ and their specific goals and mission and envisioned as a useful guide for the many affiliated volunteers who may be creating tours and a way to create consistency. It covered aspects from site selection, creating tour content, recommended word length, images, captions, references, and included a succinct 'Tour developer checklist.' The guidelines were amended and added to as the pilot project progressed. Karen explained that once work began creating tour content it was a relatively fluid process of recognising potential areas for improving on the initial ideas; working to enhance the tours composition and content, and then integrating that back into the guidance document to make future tour development projects as efficient and effective as possible.'

Both the heritage professionals and digital developers raised the topic of securing resources when asked about the challenges of developing heritage applications. Resources are a key consideration when developing mobile interpretation, and Glen is clear with his advice to heritage institutions who are considering developing an app: 'Unless you are a big organization, don't build your own app. It will be out of date straight away and will cost you a massive amount to keep it updated.' For many institutions, resources can be the biggest barrier or deciding factor for embarking on interpretation projects. He also stresses the importance of content, calling it 'the single biggest part of any project both in time and cost... If the content is great, people will use the app and tell others.' While IPENZ has an annual heritage budget, the project took a long time to launch because of the dependence on one part-time employee and volunteers. This also impacted the scope of the app, even though audio content is a feature offered by the My Tours platform it was decided that as the tour was a pilot project there were already enough challenges and audio would require additional resources and extend the project timeframe further. However, the option to have audio in the future was viewed as an asset, 'especially driving tours.'

Both Zoe and Gun discussed the need for more funding to keep developing and improve the HSS app. Gun expressed a desire to continue developing the app, create new features, and, keep it updated, unfortunately, they have not been successful so far in procuring this and 
'hence the project is kept as it was when it was first released.' When asked what she wished she had known before starting the project and what she would do differently, Zoe's primary concerns were to have secured more money so that NZ Interactive could have designed the app and HIT Lab could make an Apple version.

Karen explained that another of the challenges in creating a mobile app is making people aware of it. One target group in mind during the design process was school groups, and Karen explained that some direct marketing to schools 'could be useful' but has not yet been carried out. Some marketing and publicity was conducted by IPENZ around the time of the tour launch in mid-2015, but this was predominantly to existing members of IPENZ. Karen explains that IPENZ is 'reliant on word of mouth and also people taking it upon themselves to search online specifically for heritage tours. To maximise this exposure, IPENZ created a website entry for the Engineering Tours App to increase the chances of it showing up in search engine results and we also thought hard about the keywords submitted to Google and Apple's app stores.' This issue was also raised by Zoe who wanted to increase accessibility by advertising the app better and have devices in High Street stores that people could use.

When discussing current technology outputs and heritage requirements the managers and digital professionals expressed a strong desire to keep things simple and not feel pressured to implement flashy features for the sake of it. Glen says: 'we do think very carefully before implementing any new features on the platform so we can keep things as simple as possible. Our key requirement is that it benefits the end user. While fancy AR/VR might make a great demo, it seldom makes a great user experience.' Gun describes the app development as a complicated process that requires both the developer and client to collaborate closely. The process becomes 'much easier and fluent' if both sides keep an open mind and attempt to understand the others point of view while keeping communication lines open: 'developers needs continuous input on what the clients are expecting and what aspects of their exhibitions they would like to highlight.'

When asked about the approach to developing a heritage application in comparison to other types of projects, Gun explained that the process was similar and it was key to be clear about the goals and message of the project. The application then goes through 'several iterations of 
design-prototype-evaluation process, where we start with a very crude prototype version of an app and continue adding features and polishing the design based on the feedback from the clients and potential end users.' This evaluation is necessary for the final product. When asked what the HSS app does well, Gun responded by discussing the point of difference in using the augmented reality technology: 'The main differentiating feature of the app is the $\mathrm{AR}$ visualization where it provides three-dimensional visualization of the streetscape. In this way, the app provides the content within the context of spatial locations of the buildings and gives a better understanding of the environment which is hard to grasp when watching the content on a computer screen sitting in a room.'

When asked about the biggest limitations affecting the design of mobile apps currently, Gun explained that several factors go into designing an app that make it a time-consuming process. Things like different screen sizes, different operating systems, and different features mean 'it is challenging to meet the requirements of all of them and make sure the app runs smoothly for everyone.' The fast pace of new technology means that apps need to be tested on various kinds of phones and tablets and updated to keep up with 'changes as the old devices become obsolete and new devices are introduced to the users.' Glen also mentioned the "constraints" of screen size, memory, budget, time, and network connectivity; however, he did not see these as limitations but merely part of the problem-solving and design process.

Future planning is an essential part of any digital development, but especially for mobile applications. Without maintenance and updates, they quickly become obsolete. The concept of obsolescence was brought up in several interviews, and ongoing maintenance was discussed when asked what the app could do better. For Glen, he felt that an advantage of the My Tours platform was: 'We're always updating and upgrading the app platform so you can be sure our app will always work on all devices.' Gun explained that there is always room for improvement and mobile applications need 'continuous improvement to extend its lifetime as the technology grows old and becomes obsolete.' Zoe would like to find more funding to make sure the app continues; this would also allow it to be advertised more widely.

Karen suggested that in the future people searching for heritage tours will encounter 'a series of obsolete tours or ones which have not been updated as technological options have 
expanded. Therefore, I imagine there will be a growing number of tours which people will download and then delete without completing because they find them unsatisfactory.' This informed part of the decision-making process in choosing the My Tours platform and assigning a staff member to update and maintain content. In comparing the two options, Karen points out that while a native app has a one-off cost to build, 'there is an element of it being frozen in time.' The My Tours platform meant more flexibility, especially in future maintenance: 'content writing and loading could be done in-house easily and efficiently by approved staff. If, for example, it was discovered a link within a tour was no longer valid then a staff member could correct it quickly, whereas with a purpose-built app it may not be worth the cost of an update unless there are a batch of revisions to complete.' Using the platform also meant that it would keep up with upgrades made to the operating systems, the company updates and modifies their system accordingly. That the platform is also compatible with both Apple and Android made it attractive. The annual on-going cost for the subscription could be factored into IPENZ's annual heritage budget. Karen concludes, that the cost, 'was felt to be worthwhile and appropriate because of the flexibility the platform offers and IPENZ not needing to concern itself with background systems maintenance and upgrades for the app's continued viability.'

The heritage professionals were asked to reflect on heritage more generally and how mobile apps compare to more traditional interpretation techniques such as brochures, graphic panels, and static signage. Zoe was enthusiastic about interpretation panels, maps, and brochures that are done well. For her, their tactile nature is appealing and being able to hold them, draw on them and pass them around adds to the experience. She also commented on the communal aspect of brochures and panels, especially in the case of families, saying: 'you stand and point and talk and read together. Apps are very prohibitive in this way and quite individualistic in the way they are used which really disagrees with my idea of how good museums engage with their visitors.' Zoe went on to share an anecdote about her trip to an Italian museum which exhibited a 5000-year-old iceman which highlights the way technology can fall short of its expectations:

It was a very simple museum but thoughtfully conceived, there was one big interactive that was not really for children at all but kids swarmed around it waving their hands about watching it move the change, but there was absolutely no educational value in it at all for children using it this way. At the other end of the museum there were kids weaving by themselves and trying on the replica iceman clothes, they were being educated by doing. 
Zoe explained that museums and cultural institutions could feel pressure to install interactives, especially for children, "as they are conditioned to think they are "fun" and "modern." She countered this line of discussion with the fact that there are excellent examples of such interactives being done successfully and explained that for the particular case of HSS 'there was no other way you could achieve what this app did with 2D panels or brochures. The space, for one thing would never accommodate all those words and the 3D visuals, impossible.' However, she does not 'believe in using technology for interpretation for the sake of it' and concludes by saying: 'For me, this technology is about connecting with people's hearts through storytelling, not about gadgetry or modernity but by using it as a vehicle to touch people... [and remind] you of your own history.'

For Karen, mobile apps allow the opportunity to 'bring the threads of more traditional sources together.' They draw on similar techniques as a hardcopy walking tour brochure:

They can tell a site specific, concise and informative story, giving the user the experience of the place at the same time as taking them back to another time through the use of narrative and images. By putting this into an app form, the user's experience can be more interactive and supplement existing on-site interpretation.

This reflects the argument put forward by Wellington and Oliver discussed in the literature review, which suggests that the most ethical approach, especially regarding accessibility, is to combine physical and digital interpretation.

The professional perspectives gathered through the interviews showed that a key challenge for professionals is prioritizing the marketing and promotion of the mobile application and conducting follow-up visitor studies to formally assess their success. These aspects tended to be secondary to the digital product as they compete for limited resources, both in terms of time and funding. The next section brings in these visitor perspectives and discusses their experience of using the applications. 


\subsection{VISITOR PERSPEGTIVES}

This chapter looks at the information gathered regarding visitor experience. It begins with an overview of visitor characters which includes their previous experience with heritage interpretation, their mobile technology habits, and basic demographic information. Next, is a summary of the interviews conducted with visitors to the heritage sites who used the mobile applications. These are organized by thematic analysis, which are: intangible values and personal connections; features of the applications, including content, sites, video, audio, and photographs; application evaluation; experience of technology; and, the relationship between physical and digital.

\subsection{Visitor Characteristics}

In total, there were 30 responses to the online survey. However, there was a high percentage of incomplete answers. A response was counted when the respondent clicked away from the study description page and into the first question of the survey. This meant that those simply clicking the link to read more about the study were not counted in the total. Out of the 30 responses, 11 people completed the questionnaire. Of those 11, nine finished the tour and were interviewed, they are shown in Table one. Five participants used the IPENZ Engineering Tours mobile app and were interviewed. Four visited High Street using the High Street Stories app and participated in an interview.

The respondents had a certain level of digital literacy, all 11 surveyed owned a smartphone; of these eight were Apple iPhones and three were Android. All participants had downloaded an app to their phone in the past 12 months and answered that they used their phone daily. This was higher than the averages found in the Research New Zealand Survey, however, because the topic of the research regards smartphones it might be expected that all were frequent users who self-selected to participate. 
Table one: Visitor characteristics and background

\begin{tabular}{|c|c|c|c|c|c|c|c|}
\hline Visitor & Age & $\begin{array}{c}\text { Heritage } \\
\text { site \& app } \\
\text { used }\end{array}$ & $\begin{array}{c}\text { Previously } \\
\text { used } \\
\text { heritage app }\end{array}$ & $\begin{array}{c}\text { Previously } \\
\text { visited } \\
\text { heritage site } \\
\text { (within past } 12 \\
\text { months) }\end{array}$ & $\begin{array}{l}\text { Smartphone } \\
\text { ownership }\end{array}$ & $\begin{array}{c}\text { Downloaded } \\
\text { an app in the } \\
\text { past } 12 \\
\text { months }\end{array}$ & $\begin{array}{l}\text { Frequency } \\
\text { of app use } \\
\text { on personal } \\
\text { smartphone }\end{array}$ \\
\hline Fern & $30-39$ & IPENZ & N & N & iPhone 4s & Y & Daily \\
\hline Stuart & $40-49$ & IPENZ & $\begin{array}{c}\text { The Reefton } \\
\text { Powerhouse } \\
\text { Walk }\end{array}$ & $\begin{array}{c}\text { Kororipo Pa \& } \\
\text { Kainga, Bay } \\
\text { of Islands }\end{array}$ & iPhone 5s & Y & Daily \\
\hline Will & $16-19$ & IPENZ & N & N & $\begin{array}{c}\text { Samsung Galaxy } \\
\text { S4 Mini }\end{array}$ & Y & Daily \\
\hline Sarah & $30-39$ & IPENZ & N & N & iPhone & Y & Daily \\
\hline Mark & $30-39$ & IPENZ & N & N & iPhone & Y & Daily \\
\hline Ryan & $50-59$ & HSS & N & Pompeii, Italy & iPhone 6 & Y & Daily \\
\hline Abbie & $30-39$ & HSS & N & N & iPhone 6 & Y & Daily \\
\hline Dylan & $20-29$ & HSS & $N$ & N & iPhone & Y & Daily \\
\hline Heidi & $20-29$ & HSS & N & N & Android & Y & Daily \\
\hline
\end{tabular}

None of the participants had used the High Street Stories or Wellington Heritage Walking Tour mobile applications before and only one had used a heritage app in the past, The Reefton Powerhouse Walk. ${ }^{1}$ Two participants, one at each site, had previously visited as a heritage destination. One through a high school field trip to High Street and the other participated in the development of heritage interpretation at one of the sites in the IPENZ tour. Three answered that they had visited a heritage site within the past 12 months; their answers contained both domestic and international examples. One had been to the Kororipo Pa and Kainga site in Kerikeri, Bay of Islands, another visited Pompeii, Italy, and finally, one visited the Ferrymead Heritage Park in Christchurch.

The only demographic data collected was the age of the participant as it was not deemed relevant to gather data on income, gender, or education for this study. The greatest number of participants were within the 30-39 age bracket with four, followed by three in the 20-29 group. There were two participants in the 50-59 bracket and one each in the 40-49 and 16-19 brackets.

\footnotetext{
1 This was reveiwed in the Mobile App Appraisal, see Chapter 3.4.
} 


\subsection{Visitor Experience}

Following their visit to the heritage sites using the mobile applications, visitors were interviewed about their experience and their evaluation of the app.

\subsubsection{Intangible Values and Personal Connections}

When asked about what they seek from a heritage site there was one concept that came up more than once for respondents of both apps: learning something about the city you live in to illuminate and bring context to sites you might pass every day but think nothing of. The participants talked about "seeing things differently" once you learn something about a site or an object and how that adds value and meaning. Buildings went from simply being old to being important because of their history and context. The participants from both heritage sites were already familiar with their corresponding cities, and the app seemed to create a deeper relationship or connection for them with the place.

For Sarah, learning about the history of a place means 'your awareness adds value... and it becomes more special.' Mark talked about walking past the same buildings in his everyday life but not noticing or paying attention to them until he was able to 'put them in a time frame.' For him, putting buildings within that context and within the narrative of history was really 'illuminating.' For the visitors on the IPENZ tour, one building was identified by Mark, Sarah, Stuart and Fern as changing drastically in their opinion once they had read about its history: The Telephone Exchange Building. They discussed its unusual appearance and having passed it but not known about its history; learning about its function gave it meaning and made it more remarkable in their eyes.

The stories in the application allowed for connections with the cityscape but also with the people who populated that environment in the past. Many participants talked about the people who had lived in the city; some imagined them in the landscape now, others spoke of the way that shapes culture and experience in the present day. Ryan found it 'fascinating' to be able to walk along High Street and finding a building or site that a story in the app was referring to and 'it made it so much more interesting as I attempted to visualise the activities being talked about, happening in that exact place. [It] made me feel a little special.' The act of visualising and imagining how a site was in the past was an important part of the experience for Abbie: 'The most important part of visiting a heritage site is learning about the 
history of the place and seeing how the present state relates to that history... seeing the place and trying to imagine how it once was.'

Fern stated that what she wants out of a heritage site is 'to be reminded of the history of the area and what it means to think about the people that have come before and think about how those experiences in the past shape people's experiences today.' The connection between the past and the present and the relationship between cityscape and people was a key factor. By weaving the buildings into the narrative of the city, history added 'dimension' to them, for Stuart this meant 'it becomes more than just a building... it becomes a part of the story of the people... it becomes part of the human story.' He noted that as you learn more about a city's history, you begin 'to hear names of people, business people, entrepreneurs, politicians, quite often specific people are integral in the development of some of those historical sites...You start to get a picture of how some people have a big influence on the evolution of a city and of infrastructure.' This helped to create relatable connections to the surrounding built environment and 'joining those dots helps to bring those buildings or artefacts to life.'

\subsubsection{Features of the Application}

\section{Length and loop}

The participants using the IPENZ tour were all from Wellington, and many of them said they skipped or spent less time at those sites they were already familiar with, these tended to be the more standard "tourist" sites such as Te Papa and Parliament. The length of the tour was a point brought up by all the participants, and some wanted more flexibility in the order they went to the stops or the choice to do a short or full-length version of the tour. For some, fatigue set in at the end, both physical and mental.

Despite the length of the tour, having a reason to go out and walk around the city was positive for many of the participants. For Fern, 'It wasn't really important that I went to all the sites in a particular order' or that she went to all the sites. Both Will and Sarah suggested having a shorter version, which would help to keep interest through to the end. Will stated, 'It was a good walk, but it was a long walk. So, near the end, it was hard to stay interested... I thought they could probably cut out a couple of stops.' However, having a reason to get out 
and explore the city was positive: 'It was a good excuse to go for a walk, give you an objective, an incentive.'

Unlike the IPENZ tour, the HSS application is not a structured tour and fits within a smaller physical area. Participants, therefore, could design their navigation of the site depending on what took their interest. Ryan had read and listened to some of the stories before arriving on site and therefore had some idea of his interest. Upon arriving: 'I opened the app and looked for any points of interest that I might want to visit first...I started at the corner of High and Cashel Streets. My plan was to walk along High Street from that point and try to identify as many points of interest that were shown on the app map.'

\section{Content}

The two applications used different features to deliver most of the content: for the IPENZ application this was primarily done through text entries; for High Street Stories this was done through an audio clip with a short text entry. Participants using the IPENZ app mentioned the length and style of the writing, with most calling it informative and considered it an appropriate length. Sarah described the content as 'comprehensive,' and for Mark it was 'short but simple, in a few paragraphs [it was] explaining quite a lot.'

For Fern, the engineering focus of the IPENZ tour was initially worrying as she did not consider herself to be particularly interested in the subject, however the style of writing was appealing: 'It did have that definite engineering type focus and to start off with I was kind of like [makes a worried face]... but then it actually was quite good and gives you a different perspective on it. After my initial kind of reservations, it was good.' However, another visitor, Stuart, wanted more in-depth content: 'Perhaps, some of the text could also have been a little bit more specific. I got the feeling that it was, ah, I don't like to say dumbed down, but, it's quite hard with a word count that short to actually express any complex sort of ideas.'

Dylan visited High Street and was not particularly interested in heritage, history, or cityscapes. For him, neither the content nor the technology were enough to make the experience particularly interesting or engaging for him: 'It wasn't really the sort of history I would enjoy, there was the occasional story that had some interest but not overwhelming.' 
Although he explained it was 'still nice to learn something new' he described the content as 'not very interesting' and 'a bit boring.' However, Dylan did comment that if the app was used in a way that related to a topic he was interested in it would be successful. He had a strong interest in animals and nature and thought it could be used as a field guide:

It would be cool if it was used on a DOC [Department of Conservation] track and with trees you could learn about, with a natural history focus on animals and plants. It would be good with sites that were out of the city and you could walk through nature with it and identify the different plants.

\section{Images}

In the IPENZ tour the photos were popular for almost all the visitors, who either said they thought they were the most successful feature or would have liked even more. For Fern, the photos were a way of 'seeing the contrasts' and changes in the cityscape. They were successful as a tool for placing the site within context: 'sometimes [with] historic photos it's a bit hard to tell where you are or where things are, so there were quite a few good ones I thought that enabled you to see, you could kind of get your bearings.' Sarah felt that without the photos the tour would not have been as successful: 'I thought the photos were good and quite important to the tour. Without them I felt like it would really have suffered a lot.' For those visiting High Street the photos were a way to illustrate the site and the era that was being discussed in the audio clips: 'the pictures were a good indication of the activities of the era.'

\section{Video}

The videos were not as successfully received as the photos in the IPENZ app, with many participants either watching them at home rather than on site, or forgoing them altogether. Mark and Sarah took the tour together did not watch the videos on site because of concerns about using their data. Stuart commented: 'To me video doesn't matter so much but audio could be good.' Fern watched the videos at home, rather than at the site, she found the Wahine video very informative and it made her rethink that particular site. Fern later reflected that she probably wouldn't have watched the videos at the site anyway because of the noise at the site and 'you'd have to find somewhere shady so you could see the screen.'

\section{Audio}

Audio was a feature that emerged as being a favourable option for delivering content. The HSS application featured an audio clip for each site and was primarily based on the oral 
histories of the area. The My Tours platform offers audio as an option, however, this was not used in the IPENZ tour and several participants commented that an audio feature would have enhanced the experience for them. Sarah was heavily focused on audio and discussed having a kiosk where you could push a button to hear things like bird calls. For this participant, reading content was not their preferred way of learning or absorbing information:

I would have liked to have it read to me, with headphones and then it would have been... an experience that you could share as well because you could either wear one headphone each... When you got there in real life and then you have to read it, it kind of feels a bit weird [laughs]....Maybe it's just me because of the way I like to learn things.

The style of the audio delivery in High Street Stories was appealing for several respondents, who noted the casual tone of the clips and their relatability. Using several different senses to experience history was noted as being important. Ryan found all the stories informative and found it 'interesting listening to people just having casual conversations about the history of the areas in the High Street vicinity.'

\subsubsection{Evaluation Questions}

Participants were asked a series of 'evaluation-based' questions to garner their assessment of the application that could be compared to different users. First, they were asked if they would recommend the app to a friend and why or why not. Most participants said they would recommend the application to a friend, however, they had specific conditions under which they would offer the recommendation. For the IPENZ respondents, this would either be endorsing a portion of the tour or an abridged version, recommending it to tourists or those with a large portion of spare time. For both apps, they would recommend it to people they knew who had an interest in the subject matter, whether that was engineering or architecture, or history and the city of Christchurch.

Will thought it was a good experience to be active and learn at the same time, however, thought 'you have to actually have a base interest in the actual subject' and would be selective in who he recommended it to: 'I don't think I would recommend it to just any of my normal friends but definitely, if I knew someone who had an interest.' Stuart thought it would be a good experience to recommend to an overseas visitor, who has time and wanted to learn 
more about the city they were visiting. He would recommend the app to a visitor with those characteristics regardless of their interest in architecture of engineering. If he were to recommend it a friend or someone similar to himself, who had grown up in Wellington, he would first assess their interest in engineering, because 'the content wouldn't be interesting enough to pull you through the whole experience.'

Sarah seemed to have a clear picture about the type of characteristics a person who would enjoy the IPENZ tour would possess, one of them being introverted:

I mean [Mark's father] would be a perfect candidate because... if he came to Wellington he would be a tourist, he's a guy that likes to walk, he walks on golf courses, and he's capable physically and he's a civil engineer.... He would actually love it [laughing].... He's quite introverted and he's quite happy to read.

There were two participants who said they would not recommend the app to a friend, one from each app, the reasoning being that they did not think their friends were the right demographic and would not be interested in the subject matter. Dylan did not connect with the content of the tour as it was not a subject he was usually interested in and therefore would not be quick to recommend it. Will thought that his peers were not the targeted demographic, he was in the 16-19 age bracket and could not 'imagine a bunch of 18-year-old boys walking around town reading about the history of Wellington. It's not very realistic, these days.'

Participants were then asked if they would visit the sites again or use the app again. For both applications, some said they would be revisiting the sites in their everyday life. For the IPENZ app respondents said they could use the app as a reference guide, others were interested in trying the Auckland version of the tour, however, none were definite that they would do the full tour again. Will described it as 'definitely a one-time thing in my opinion,' and both Dylan and Heidi using the High street Stories would not return again also calling it a onetime experience. This indicates that such experiences may have a shelf-life, however, unless the goal of the site is to create return visits, this is not necessarily a negative.

Fern said she would travel past several of the sites in her day to day activities and imagined she would think about the things she read in the app, especially regarding the Kumototo Stream, however, 'I don't know if I would pick up the app while I was there and read it 
again.' Mark and Sarah were interested in taking the Auckland tour as it is a city they are unfamiliar with, unlike Wellington. They thought it would be good to compare the experiences, especially having to take the directions of the app seriously and 'be more guided around... because you don't actually know where to go.' Ryan wanted to return to High Street to spend 'more quality time looking around the areas,' but also at a time in the future 'once a lot more of the street is open to the public, as a substantial part of the it is still fenced off due to earthquake damage.'

\subsubsection{Technology}

When asked to rate the application with a score out of ten, the participants generally rated both very highly, with most giving scores of seven or eight out of ten. However, the justification given for the score was usually less enthusiastic and related to the app meeting their expectations or there being nothing particularly wrong with the applications. For two participants, issues with technology or the interface influenced their score. Mark scored the IPENZ app an eight because 'it did everything I thought it would.' His expectations were met and therefore he felt it was a successful guided tour. Whereas Will rated the app a seven 'because there's nothing absolutely wrong with it.' Although it did not exceed his expectations or surprise him, it was still effective. Stuart had a similar justification for giving the app a seven and a half: 'it's good but it's not great. There is nothing fundamentally wrong with it... if you've got a good sunny day and you're in the mood for a walk there's lots of valuable information in there, general information which a lot of people would find interesting. It's easy to download. It's simple to use.' Ryan rated the HSS app a seven out of ten, but explained it was not due to the content but because it was not available on iPhone and he also found the navigation difficult on the small screen of a smartphone. He had issues with the limitations of the screen size using it in-situ and found it easier to navigate the website on a desktop computer.

When asked this question Sarah, who used the IPENZ app, wanted clarification on what was meant by rating "the app" and making an assessment, asking whether to rate the technical aspect or the content, which for her, were two very different things. From a content perspective, Sarah thought the application was successful, but making an assessment on the technical function or technology used, the application fell very short of her expectations and what she imagined are the possibilities that digital technology offer: 
For me the content and the technical are quite different. Technically, I would rate it about a two because I feel like it's a slide show, it's quite easy to produce technically. [But] as a resource, probably about an eight.... It had some pretty awesome stuff, [and was] well written.

This topic was discussed again in more detail further along in the interview, where Sarah explained what her expectations are from digital technology, which involved a much more interactive and responsive interface: 'I think given the technology and the amount of amazing brains and people there are out there that can make some pretty awesome apps...' Sarah felt the tour would have been just as successful on a printed brochure and making digital didn't enhance it. When downloading something from the App Store her expectations are that it should be responsive and there should be dialogue and interaction. She felt that the main focus of the app was content and that, in fact, this is where the focus should have been. She also commented on the increases in resources she expected this would require: 'I'm assuming that you would need more resource, more money, more people, to be able to do everything else, you know there would be a lot of extra finance needed... to get it really so it's like an attraction.'

Stuart felt this way about many of the mobile applications they used regularly, even the ones they felt were successful. They felt there was a lot of room for improvements to mobile applications generally to make them more intuitive and the interface more responsive, especially given the limitations of screen size. He compared it to several news apps he uses regularly, Stuff and BBC, stating that although they have a huge investment and design development, 'even still some of them can be not quite 100\% intuitive.' Stuart believed there was still room to improve on the interface of apps and those used on smartphones in particular.

Several of the respondents from both apps talked about their experience with the technology from a physical standpoint. For Mark and Sarah, who took the IPENZ tour together they took one phone between them, however they found this affected their experience on the tour and thought it was more suited to being a solo experience rather than a collective or joint one, in particular because of the act of reading the content. From a social perspective, Sarah thought the act of reading was something better done individually, or alone. She felt the tour 
was suit for an individual, 'it feels like it's designed to really cater for someone whose able to just, head down, and can get real into the content.'

For two other participants using IPENZ, physically holding their phone in their hand as they walked through the tour was an unusual experience, or different from the usual use of their phone. Will explained that the locations visited in the latter part of the tour were closer together which meant he had is phone out of his pocket and in his hand more often. He described not being able to put the phone away and feeling 'uncomfortable' having to keep hold of it. Stuart called it an 'interesting experience' walking around the city holding his phone, even though 'a lot of us do that most of the time anyway, [but] because we were using the phone for this different activity it seemed a bit strange.' He thought it would be different again if the experience was an audio tour, where you could keep your device in your pocket and just had headphones.

Respondents of both applications were also quick to point out when something had gone wrong with the technology, for example, if a video failed to load or did not play or when a photo gallery did not respond to the swipe gestures. These caused some frustration and annoyance. For all the participants using the HSS application, they owned iPhones rather than Android and therefore had to borrow phones or use old ones to take the tour which caused some frustration. However, there were no further issues with the app once it was downloaded.

\subsubsection{Digital Versus Physical}

One phenomenon that was discussed by all the participants was the relationship between the physicality of the site and the mobile application operating in a digital sphere. Some of the sites had physical interpretation, for example, plaques or signage, whereas other locations were broader, for example, Mercer Street being an entry as an entire street. Some respondents discussed creating trigger or entry points, something physical at the site that would notify you of the fact that content was available through the application. The order of experience would be reversed, where the physical interpretation leads them to the app rather than the app leading them to the particular heritage site. The comments seemed to point to a 
desire for discovery, where you could "stumble upon" a site rather than being instructed to go to it.

Other respondents talked about having a physical marker at the site to notify you that you have "arrived" to mark the site; a unifying feature that would connect the tour in the physical environment and would be a visual or physical beacon of the presence of the tour. Sarah suggested a kiosk. For Stuart, it was harder to connect to a particular site because it didn't have the same physical remnants or presence of the other sites. He thought a symbol or logo that connects the site with the app; this would help 'give you the impression that you've arrived at the exact site.' Mercer Street had archival photos of the site, but no physical artifacts or remnants, which made it difficult to relate to as 'it wasn't a discrete object it was a street... so it was hard to engage with that particular site.'

Overall, participants described having positive experiences and talked about learning new things through the app. For many, learning the history and context added value to the sites and helped visitors create more personal connections. They described aspects of their experiences which began to resonate with the concept of Numen: deep engagement, empathy, and awe. The visitors provided tangible feedback on their experiences which can be acted on by the heritage managers of these sites and used to evaluate the app in relation to their wider interpretation goals. These insights were only possible through formal visitor studies and show their importance in developing and evaluating heritage projects. 


\subsection{DISGUSSION AND GONGLUSIONS}

The primary question of this research asks what kind of visitor experience do mobile applications provide at heritage sites in Aotearoa New Zealand? The secondary questions of the study were designed to explore the topic in more depth and to elicit perspectives from both visitors and heritage professionals. The experience of the participants' visit to each heritage site using the mobile apps is discussed below, followed by an outline of the challenges faced by professionals in designing the heritage apps and several recommendations for future projects. Finally, recommendations for further research is considered.

\section{Visitor Experience}

An overwhelming aspect of the experience of heritage sites was the participants' connection with the social and physical aspects of the cityscapes. This was done through a connection with the content or the stories that were shared through the interpretation and the act of being physically at the site of the histories presented. The concept of Numen, discussed in the literature, helps to frame the kind of experience visitors had using the mobile apps. Conceptually, there are three aspects to numen: deep engagement; empathy, 'a strongly affective experience in which the individual tries to conjure the thoughts, feelings, and experiences, including hardships and suffering, of those who lived at an earlier time'; and, awe or reverence. While some aspects of deep engagement and awe were apparent, several visitors expressed a sense of empathy during the interviews. They discussed conjuring visions of people in the past living within the cityscapes, imagining how they might have experienced the landscape and how their experience compared to theirs, especially with the changes that have occurred. They expressed a sense of awe at the achievements of these people through the changes made to the environment through the development of the built heritage and cityscape.

Visitors frequently talked about the educational aspect of the experience and learning being a large part. However, this was often in the context of learning something about their familiar environments that changed or challenged the way they perceived them, moving beyond simply acquiring new knowledge. It was a far more personal experience where visitors began 
rethinking and looking differently at the sites in the tour, especially those they may have encountered many times in their everyday activities.

It was the connection with the content and the narratives, rather than the vehicle of interpretation that made the experiences meaningful. Reflecting the ideas of interpretation examined in the literature review, there was evident power and appeal of stories to the audience. Visitor experience did not seem to be necessarily enhanced or diminished simply because the content was digital. Visitors' expectations for mobile were focused on ease of access and content that is tailored to their interests and needs. This highlights the need to design experiences from a user needs and motivations perspective rather than a technology perspective. This was especially true for the visitor who was not interested in the subject matter and therefore found the experience underwhelming but would have engaged more if the content was related to their particular set of interests.

Falk and Dierking, who advocate for a focus on a needs-based understanding of visitor behaviour, assert that people visit museums to satisfying certain needs and hold particular expectations. ${ }^{1}$ For many of the participants, they had expectations of what a heritage tour should do and ideas about what technology can offer. For those whose expectations were met the tour was successful. They often measured this by learning something and finding material of interest. However, for a few participants, the expectations of the potential for digital technology outstripped the reality of what the application could achieve. For those who had high expectations, they were inevitably disappointed. Small technological issues were a cause for annoyance to some visitors and prompted them to rate the applications lower despite their favourable opinion of the content. Respondents commented when a video didn't load, or a photograph gallery did not operate smoothly, and some chose to forgo part of the content due to data usage.

There are several features that digital technology offers that create an advantage over other interpretation tools; GPS, for example, provides a real-time, visual navigation tool which can locate users, identify sites of interest, and highlight a route. Digital galleries mean several images can be used to illustrate the stories and are not limited by the constraints of physical

${ }^{1}$ H. F. Falk and L. D. Dierking, Museum Experience Revisited, (Washington: Left Coast Print, 2012), 33. 
space. Photographs were an overwhelmingly powerful and successful tool, appealing to almost all the visitors. The digital sphere can layer information and ideas, unlike traditional methods which are often limited by word count and wall space, digital solutions can contain several information threads, from the main narrative through to separate biographies, events or stories told from multiple perspectives. Conversely, this means that the specific practicalities that come with using digital interpretation need to be well considered and designed for. Using audio on site requires visitors to have earphones; at open sites, the surrounding sounds of traffic and wind may make listening without headphones problematic. Some applications can be draining on the battery, especially those which use GPS. This requires visitors to plan and may restrict their ability to take the tour spontaneously if their battery is running low.

Visitors expressed a desire for a tangible embodiment of the tour. Despite the sites being physical visitors discussed having physical wayfinding as a way of creating a sense of destination and arrival. This echoes the arguments made by Wellington and Oliver that layering digital initiatives with analogue technologies will 'ensure equitable access to and experience of cultural memory.' ${ }^{2}$ Digital interpretation need not be developed at the expense of the physical "traditional" interpretation of the site. They can be designed in conversation with each other so that visitors can still experience the narrative of the site if they choose to take the tour with or without the app and simply adds another layer of interpretation that may appeal to one "visitor's context" and not another. Physical interpretation also allows for chance encounters by visitors, reversing the order of experience, the physical interpretation leads them to the app rather than the app leading them to the heritage site. This also plays into Jimson and Hooper-Greenhill's promotion of fun and entertainment as a crucial part of interpretation. The idea of heritage being 'worthy, and fun' reflects the visitors' discussion of curiosity and discovery, where they could "stumble upon" a site rather than being instructed to visit. However, designing for both physical and digital interpretation increases the strain on resources and widens the scope of such projects. This needs to be weighed against the aims of the overall development.

\footnotetext{
2 Shannon Wellington, and Gillian Oliver, "Reviewing the Digital Heritage Landscape - The Intersection of Digital Media and Museum Practice," in The International Handbooks of Museum Studies: Museum Practice, First Edition, ed. Conal McCarthy, ( John Wiley \& Sons, Ltd., 2015), 589.
} 


\section{Challenges for Heritage Professionals}

Given the speed of change impacting both technologies and behaviors and the often significant costs associated with developing mobile technology, there are substantial challenges facing heritage professionals. Resource was identified as one of the key challenges for professionals, which impacted their ability to carry out aspects of the research they wanted. For HSS this impacted on the mobile being available through Android compatible devices only, alienating a portion of potential users. For both projects, it has increased their concerns for keeping their applications updated and relevant for the future. Mobile applications require an investment of resources, using considerable amounts of both time and money to develop and sometimes means that visitor studies are put second to the development rather than driving projects. Karen expressed a desire for this to be carried out as one of the next steps for the IPENZ Engineering Tours project and explained that choosing a pre-built platform meant ongoing maintenance costs could be factored into future budgets, and provisions for keeping the app updated written into policy.

Accessibility is a key challenge for professionals. Although downloading an app is as simple as "clicking a button" it is extremely difficult to get people to download a new app. The driver is often either curiosity or a perceived need but when, where, and how should institutions ask users to download it? At home? At the museum? On their way to the heritage site? While some visitors may download the app before arriving on location, some will not, and they will be influenced by things like download speed, personal data use, and, provided WiFi. If WiFi is not being offered, the $3 \mathrm{G}$ and $4 \mathrm{G}$ signals should be strong throughout the various sites to allow for ease of download. This also highlights the effect the size of the application has on encouraging users to download it, especially if they are using their personal data.

Accessibility is also affected by awareness. There needs to be a budget for press and promotion, particularly for mobile applications which need to be actively sought and downloaded. Often advertising it is left to word of mouth and potential visitors searching online for heritage tours rather than targeted advertising campaigns. It is hard to create chance encounters; therefore, entry points for the visitor need to be carefully considered. This can be done through mobile advertising with programs like Google Maps, or targeted advertising through Facebook, Instagram, or Twitter advertisements and promoted posts. Or, through physical advertising at the sites themselves in the form of wayfinding or $\mathrm{QR}$ codes. 


\section{Recommendations for Practitioners}

The increasing prominence of mobile applications in everyday life and the impact this has on lifestyle and habits means the field of heritage mobile development is an important one. With the increasing numbers in smartphone ownership, it seems counter intuitive not to invest in their potential. For practitioners looking to add mobile interpretation to their digital strategies, several important considerations from these case studies have emerged which could be used to inform practice:

Visitor studies should be a key part of the development process. They can be used to help understand the expectations and behaviours amongst visitors to the heritage sites. Identifying a target audience can help drive the project and understanding general mobile behaviours can contribute to improving the experience for visitors. For example, if visitors are taking their own photographs at the heritage site might this be facilitated or encouraged in a mobile application?

"Digital" is not a one-size-fits-all solution, and clear aims and goals should be established to help drive the project. These should fit into the wider strategies and missions of the institution and complement other projects.

Technology should be used to create interpretation that is not easily replicated through other, static methods. Take advantage of the particular functions offered by smartphones, such as GPS, push notifications, social media functions and audio.

Budgeting for press and promotion so that visitors know the application exists and can make use of it. This is particularly important for mobile applications which need to be actively sought and downloaded.

Consider physical interpretation alongside digital solutions. This could be as simple as a bollard or plaque at each site to bring the digital tour into the physical world in a tangible way. This can also be harnessed to enhance awareness and accessibility to discovering the mobile application and the tour.

Awareness of the logistics of using technology at the heritage sites is critical. This includes considerations of: earphones; $\mathrm{WiFi}$ and $4 \mathrm{G}$ networks; personal data usage; 
noise or light pollution at open sites. Identify what factors impact or impede experience for visitors.

Pilot projects can be a good way to begin implementing a mobile strategy and to test visitor reception. This can help determine the scale and nature of opportunities and support continued investment in digital projects. Tour suites like the IPENZ Engineering Tour allow for future developments and continuation depending on the outcome of the initial project.

Developing a mobile application for heritage interpretation is an ongoing and evolving process; it does not end once the app is released on the App Store. Continued marketing is needed to ensure accessibility by making sure potential visitors are aware of the experience. Planning and budgeting for future-proofing and updates will ensure the app remains relevant and available for visitors. This also opens avenues for repeat visits and ongoing use of the app as a resource, if this is a goal of the project. Visitor studies bridge the gap between theory and practice and should be prioritised at all stages of the project.

\section{Recommendations for Further Research}

The framework of this investigation is offered as a platform to further studies with a broader scope. Using a larger sample of visitors would benefit future projects. A further avenue of research would be to investigate a case study where the site offered both digital and physical interpretation to compare the two methods and how visitors experience the same heritage site through the two mediums. This could also be used to examine how the two techniques can work in unison together. Another important aspect to investigate is the general mobile behaviours of current heritage visitors, to understand what their attitudes are towards mobile technology, what services and applications do they already use, and, what is their current use of smartphones and mobile devices during cultural visits. A case study that looks at visitors operating a heritage mobile application through close observation would investigate exactly how they interact with the interpretation tool. Finally, examination should be made into the marketing and promotional strategies of mobile interpretation to investigate the issue of accessibility and how best to prioritise resources when creating such experiences. 
This dissertation presents research designed to investigate the kind of visitor experience provided by mobile application interpretation, using High Street Stories: the life and times of Christchurch's High Street Precinct and IPENZ Engineering Tours: Wellington Heritage Walking Tour apps as case studies. The aim was to explore the value of mobile applications in heritage interpretation by following a qualitative approach and to test the digital promises made by digital technology through empirical investigation. The use of Smartphones and mobile applications that underpins this research demonstrates an effective method of bringing together the physical traversing of landscapes with digital tools to create a layering of narratives, people, events, and voices. Heritage trails, by taking the visitor to the physical site of historic events, have the potential to offer a strong sense of place, identity, and Numen for visitors.

This study took its cue from the rising popularity of digital technology used in interpretation and the increased investment in mobile applications. Through a literature review, documentary research and case study fieldwork, this exploratory study has identified the gap between the theory and practice of using mobile applications as interpretation tools in Aotearoa and illustrated how we might begin to bridge this. It indicates that empirical studies which combine the interests of both visitors and professionals allows for deeper understanding and insights and, highlights the importance of visitor studies when undertaking any interpretation project, but especially those that include mobile applications. This study presents a foundation on which to continue research into digital technology and advocates for balancing these new tools of communicating with traditional methods, to offer multiple avenues of facilitating meaningful visitor experiences.

When undertaking mobile projects, it is important to understand visitor needs and expectations and balance this with institutional goals. While learning and education is a laudable outcome, heritage managers should draw on ideas of empathetic and experiencecentered design. The best heritage apps are sophisticated but simple. They shouldn't be made for the sake of having an app or feeling the need to be digitally relevant. They have been created because there is a role for them in the greater project or vision. "Digital," the catchall phrase that has come to mean anything from online and web, to wearables and virtual reality, is not a one-size-fits-all solution. We haven't fully explored the true potential of what this technology can do, and the unrestrained optimism for all things digital is fading. Arthur 
C. Clarke once wrote: 'any sufficiently advanced technology is indistinguishable from magic.' However, no technology will be able to replace the ability to tell a story that grips, fascinates and emotionally engages an audience. 


\subsection{BIBLIOGRAPHY}

Angen, M. J. "Evaluating interpretive inquiry: Reviewing the Validity Debate and Opening the Dialogue." Qualitative Health Research, 10.3 (2000): 378-395.

Arvanitis, Konstantinos. "Museums outside Walls: Mobile Phones and the Museum in the Everyday." In Museums in a Digital Age, Ross Parry, (ed.), 170-176. New York: Routledge, 2010.

Bagnall, Gaynor. "Performance and Performativity at Heritage Sites." Museum and Society 1.2 (2003): 87-103.

Beck, Larry and Ted T. Cable. The Gifts of Interpretation: Fifteen Guiding Principles for Interpreting Nature and Culture. Illinois: Sagamore Publishing, 2011.

Blaikie, Norman. Designing Social Research: The Logic of Anticipation, second edition. Cambridge: Polity Press, 2009.

Bowen, Glenn A. "Document Analysis as a Qualitative Research Method." Qualitative Research fournal, 9.2 (2009): 27-40.

Bryman, Alan. Social Research Methods. Oxford: Oxford University Press, 2012.

Cameron, Catherine M. and John B. Gatewood. "The numen experience in heritage tourism." In The Cultural Moment in Tourism, Laurajame Smith, Emma Waterton, and Steve Watson, (eds.), 235-252. New York: Routledge, 2012.

Caddington, Elise. "Seeing Eye to Eye? The presentation and understanding of interpretation at a New Zealand heritage site." Dissertation, Victoria University of Wellington, 2014.

Collier, Alan, and Sue Harraway. The New Zealand Tourism Industry. Auckland: Pearson New Zealand, 2005.

Cooke, Paul, Laura King and James Stark. Experiencing the Digital World: The Cultural Value of Digital Engagement with Heritage. Arts \& Humanities Research Council, 2014. Accessed 4 April 2016. <http://www.digitalheritage.leeds.ac.uk/files/2014/10/AHRG_Cultural_ Value_CR-Experiencing-the-Digitall.pdf>

Darke, Peta, Graeme Shanks, and Marianne Broadbent. "Successfully completing case study research: combining rigor, relevance and pragmatism." Info Systems 7 , 8 (1998): 273-289.

Davidson, Lee. "Visitor Studies: Toward a Culture of Reflective Practice and Critical Museology for the Visitor-Centered Museum." In The International Handbooks of Museum Practice, Conal McCarthy (ed.), 503-528. New York: John Wiley \& Sons, Ltd., 2015.

Davis, Peter. "Places, 'cultural touchstones' and the ecomuseum." In Heritage, Museums and Galleries: An Introductory Reader, Gerard Corsane, (ed.), 365-376. London; New York: Routledge, 2005. 
Davison, Patricia. "Museums and the re-shaping of memory." In Heritage, Museums and Galleries: An Introductory Reader, Gerard Corsane, (ed.), 184-194. London; New York: Routledge, 2005.

Denscombe, Martyn. The Good Research Guide: for small-scale social research projects, fourth edition. Maidenhead: McGraw-Hill/Open University Press, 2010.

Dictionary.com. “App.” Dictionary.com. Random House, Inc. Accessed 27 June 2016. <http://www.dictionary.com/browse/app>

Dwyer, Sarah Jean. "'The Landscape is Our Archive': The Benefits of a Cultural Landscapes Approach to Interpretation Practice in New Zealand." Master's Thesis, Victoria University of Wellington, 2010.

Dye, John. "77 percent of users never use an app again 72 hours after installing." Android Authority. Accessed 2 October 2016. <http://www.androidauthority.com/77-percentusers-dont-use-an-app-after-three-days-678107/>

Dyson, Evelyn, Laurel and Stephen Grant and Max Hendriks (eds.). Indigenous People and Mobile Technologies. New York: Routledge, 2016.

Elliott, J. "The researcher as narrator: reflexivity in qualitative and quantitative research." In Using Narrative in Social Research, J. Elliott, 152-170. London; Thousand Oaks; New Delhi: Sage, 2005.

Fairclough, G. "New Heritage, and Introductory Essay - People, Landscape and Change." In The Heritage Reader, G. Fairclough, R. Harrison, J. Jameson Jr., and J. Schofield, (eds.), 297-312. London; New York: Routledge, 2008.

Falk, H. F. and L. D. Dierking. Learning from Museums: Visitor Experiences and the Making of Meaning. Washington DC: Walnut Creek: AltaMira, 2000.

-. Museum Experience Revisited. Washington: Left Coast Print, 2012.

—. The Museum Experience. Washington: Whalesback, 1992.

Fell, Georgina. "Going Social: a case study of the use of social media technologies at Te Papa." reCollections 9.1 (April 2014).

Galani, Areti, Aron Mazel, Deborah Maxwell and Kate Sharpe. "Situating Cultural Technologies Outdoors: Empathy in the Design of Mobile Interpretation of Rock Art in Rural Britain." In Visual Heritage in the Digital Age, Eugene Ch'ng, Vincent Gaffney, and Henry Chapman, (eds.), 183-204. Birmingham: University of Birmingham, 2013.

Google Play. "High Street Stories." Updated 5 April 2015. <https://play.google.com/store/apps/details?id=com.hitlabnz.hss\&hl=en>

—. "IPENZ Engineering Tours." Updated 23 April 2015.

<https://play.google.com/store/apps/details?id=com.mytoursapp.android.app741\& $\mathrm{hl}=\mathrm{en}>$ 
Graburn, N.H.H. and D. Barthel-Bouchier. "Relocating the tourist." International Sociology, 16 (2001): 147-58.

Hall, Michael C., and Simon McArthur. Heritage Management in New Zealand and Australia: Visitor Management, Interpretation, and Marketing. Auckland: Oxford University Press, 1993.

—. Integrated Heritage Management: Principles and Practice. London: The Stationary Office, 1998.

Ham, Sam H. Environmental Interpretation: A Practical Guide for People with Big Ideas and Small Budgets. North American Press, 1993.

—. "From Interpretation to Protection: Is There a Theoretical Basis?" Fournal of Interpretation Research, 14.2 (2009): 50-57.

—. Making a Difference on Purpose. Colorado: Fulcrum Publishing, 2013.

Harmen, Charlie. "Native Vs. Hybrid - Which should you choose?" Cavium. Published 6 November 2014. <https://calvium.com/native-vs-hybrid-choose/>

Hayden, Dolores. "The Power of Place: Claiming Urban Landscapes as People's History." Journal of Urban History 20.4 (August 1994): 466-485.

Hein, G. E. "Studying visitors." In Learning in the Museum, G. E. Hein, 100-134. London; New York: Routledge, 1998.

Hodgkin, Katherine and Susannah Radstone (eds.). Contested Pasts: The Politics of Memory. Routledge: London, 2003.

High Street Stories. Accessed 27 April 2016. <http://www.highstreetstories.co.nz/splash>

Hollingsworth, Mat. "Not all apps are created equal: Mobile apps vs mobile-optimsed web apps." Inoutput. Publised 24 February 2016. <http://inoutput.io/articles/development/ understanding-the-difference-between-mobile-apps-and-mobile-optimised-web-apps>

Homan, R. The Ethics of Social Research. New York: Longman, 1991.

Hooper-Greenhill, Eileen. Museums and Their Visitors. London: Routledge, 2013.

Howell, Ray, and Matt Chilcott. "A Sense of Place: Re-Purposing and Impacting Historical Research Evidence through Digital Heritage and Interpretation Practice." International Journal of Intangible Heritage 8 (2013): 165-177.

Human Interface Technology Laboratory New Zealand (HIT Lab). Accessed 23 June 2016. <http://www.canterbury.ac.nz/spark/Group.aspx?groupid=122>

ICOMOS. "The ICOMOS Charter for the Interpretation and Presentation of Cultural Heritage Sites." International Council on Monuments and Sites. Updated 4 October 2008.

<http://icip.icomos.org/downloads/ICOMOS_Interpretation_Charter_ENG_04_10_ 08.pdf> 
IPENZ Engineering Heritage New Zealand. "Introduction." Accessed 27 April 2016. <http://ipenz.org.nz/heritage/introduction.cfm>

Jimson, Kerry. "Translating Museum Meanings: a case for interpretation." In The International Handboo of Museum Studies: Museum Practice, First Edition, Conal McCarthy (ed.), 529-550. John Wiley \& Sons, Ltd., 2015.

Kirchberg, Volker, and Martin Tröndle. "Experiencing Exhibitions: A Review of Studies on Visitor Experiences in Museums." Curator 55.4 (2012): 435-452.

Lee, Gun A., Andreas Dünser, Seungwon Kim, Mark Billinghurst. "CityViewAR: A Mobile Outdoor AR Application for City Visualisation." Human Interface Technology Laboratory Report. Christchurch: University of Canterbury, 2012.

Lee, Paul, Duncan Stewart and Cornelia Calugar-Pop. "Deloitte: Technology, Media and Telecommunications Predictions, 2014." Deloitte. Accessed 10 October 2016. <https://www2.deloitte.com/content/dam/Deloitte/global/Documents/TechnologyMedia-Telecommunications/dttl_TMT_Predictions-2014-lc2.pdf>

Lewis, Andrew. "What do visitors say about using mobile devices in museums?" Victoria and Albert Museum. Published 13 March 2013. <http://www.vam.ac.uk/blog/digitalmedia/museum-visitors-using-mobile.>

Loomis, Ross J. "Planning for the Visitor: The Challenge of Visitor Studies." In Museum Visitor Studies in the 90s, Sandra Bicknell and Graham Farmelo (eds.), 13-23. London: Science Museum, 1993.

Lowenthal, David. "Heritage and Its History: Menaces of the Much-Loved Past." Keynote Address to the Research Libraries Group 1999 Annual Membership Meeting. Accessed 20 May 2016. <http://www.rlg.org/annmtg/lowenthal99.htm>

—. Possessed by the Past: The Heritage Crusade and the Spoils of History. New York: Free Press, 1996.

—. The Past is a Foreign Country. Cambridge; New York: Cambridge University Press, 1985.

Masberg, Barbara A, and Lois H. Silverman. "Visitor Experiences at Heritage Sites: A Phenomenological Approach." Fournal of Travel Research 34 (1996): 20-25.

Mason, Rhiannon. "Museums, galleries and heritage: sites of meaning-making and communication." In Heritage, Museums and Galleries: An Introductory Reader, Gerard Corsane, (ed.), 200-214. London; New York: Routledge, 2005.

McCarthy, Conal. "Te Ara o Nga Tupuna Maori Heritage Trail/Te Aro Pa, 39 Taranaki St, Wellington." New Zealand Fournal of History 43.1 (2009): 114-117.

McManus, P. M. (ed.). Archaeological Displays and the Public: Museology and Interpretation. London: Institute of Archaeology, 1996. 
Melamed, Tom. "The blagger's guide to talking about apps with authority." Calvium. Published 16 February 2016. <https://calvium.com/the-blaggers-guide-to-talkingabout-apps-with-authority/>

Merriam-Webster Dictionary. "Application." Merriam-Webster.com. Accessed 27 June 2016. <http://www.merriam-webster.com/dictionary/application>

Mills, A. J., G. Durepos, and E. Wiebe, (eds.). Encyclopedia of Case Study Research. Thousand Oaks, CA: SAGE Publications, Inc., 2010.

Ministry for Culture and Heritage. "Rising from the rubble - stories of High Street." Updated 23 July 2015. <http://www.mch.govt.nz/news-events/news/rising-rubblestories-high-street>

Museum Association. Mobile Survey 2012. London: Museum Association. Accessed 5 September 2015. <www.museumsassociation.org/download?id=731198>

- Mobile Survey 2013. London: Museum Association. Accessed 5 September 2015. $<$ www.museumsassociation.org/download?id=1025016>

My Tours App. Accessed 5 May 2016. <https://www.mytoursapp.com/>

NV Interactive. "High Street Stories.” Accessed 19 April 2016.

$<$ https://www.nvinteractive.com/work/high-street-stories>

O'Connell, Oliver. "History of a thousand hands: Heritage websites in New Zealand." Dissertation, Victoria University of Wellington, 2014.

Parry, Ross. "Digital heritage and the rise of theory in museum computing, Museum Management and Curatorship." Museum Management and Curatorship 20.4 (2005): 333348.

Parry, Ross (ed.). Museums in a Digital Age. New York: Routledge, 2010.

Patton, Michael Q. "Qualitative interviewing." In Qualitative Evaluation and Research Methods, 277-359. Newbury Park, Calif.: Sage Publications, 1990.

Prensky, Marc. "What Can You Learn from a Cell Phone? Almost Anything!" Innovate Journal of Online Education. 1.5 (2005).

Research New Zealand. A Report on a Survey of New Zealanders' Use of Smartphones and other Mobile Communication Devices 2015. Wellington: Research NZ, 2015.

Smith, Laurajane, "The cultural 'work' of tourism." In The Cultural Moment in Tourism, 210234. New York: Routledge, 2012.

—. The Uses of Heritage. London and New York: Routledge, 2006.

-. "Theorising Museum and Heritage Visiting." In The International Handbooks of Museum Practice, Conal McCarthy (ed.), 459-484. New York: John Wiley \& Sons, Ltd., 2015. 
Smith, Laurajane, Emma Waterton and Steve Watson. The Cultural Moment in Tourism. New York: Routledge, 2012.

Staiff, Russell. Re-Imagining Heritage Interpretation: Enchanting the Past-Future. Farnham, Surrey \& Burlington, Vermont: Ashgate Publishing Group, 2014.

Statista. "Number of mobile app downloads worldwide from 2009 to 2017." Accessed 10 January 2017. <https://www.statista.com/statistics/266488/forecast-of-mobile-appdownloads/ >

—. "Number of apps available in leading app stores as of June 2016." Accessed 1 October 2016. <https://www.statista.com/statistics/276623/number-of-apps-available-inleading-app-stores/>

Tallon, Loïc. "Introduction: Mobile, Digital, and Personal." In Digital Technologies and the Museum Experience: Handheld Guides and Other Media, Loïc Tallon, and Kevin Walker, (eds.), xiii. Lanham: AltaMira Press, 2008.

Tilden, Freeman. Interpreting Our Heritage. North Carolina: University of North Carolina Press, 1977.

Tomiuc, Anamaria. "Navigating Gulture: Enhancing Visitor Museum Experience through Mobile Technologies." Journal of Media Research 3.20 (2014): 33-46.

Trapeznik, Alexander, and Gavin McLean. "Public History, Heritage and Place." In Common Ground? Heritage and Public Places in New Zealand, Alexander Trapeznik (ed.). Dunedin: University of Otago Press, 2000.

University of Leeds. Experiencing the Digital World. 2014. Accessed 10 April 2016.

$<$ www.digitalheritage.leeds.ac.uk>

Uzzell, D. (ed.) Heritage Interpretation: The Visitor Experience. London: Belhaven, 1989.

Wallace, Paulette. "A Fraction Too Much Friction: Contested Heritage and the Whiteley Memorial." Master's Thesis, Victoria University of Wellington, 2008.

Warren, Julie A. N., and C. Nicholas Taylor. Developing Heritage Tourism in New Zealand. Wellington: Centre for Research, Evaluation and Social Assessment Ltd., 2001.

Warren-Findley, Jannelle. "Human Heritage Management in New Zealand in the Year 2000 and Beyond." Report of the Ian Axford New Zealand Fellowship in Public Policy, 2001.

Wellington, Shannon, and Gillian Oliver. "Reviewing the Digital Heritage Landscape - The Intersection of Digital Media and Museum Practice." In The International Handbooks of Museum Studies: Museum Practice, First Edition, Conal McCarthy, (ed.), 577-598. John Wiley \& Sons, Ltd., 2015.

Yin, Robert K. Case Study Research: Design and Methods. London: SAGE, 2009. 


\subsection{APPENDICES}

\section{Appendix 1 Glossary of Terms E Abbreviations}

The Merriam-Webster online dictionary defines application as 'a program (as a word processor or a spreadsheet) that performs one of the major tasks for which a computer is used.' Dictionary.com defines app, an abbreviation of application software, as 'an application, typically a small, specialized program downloaded onto mobile devices. ${ }^{2}$ Mobile apps are software used on mobile devices rather than software that is accessed and used online, via a browser and often incorporates elements of rich media capable with the device, such as video, photos, three-dimensional models, and audio, and follow the user navigation capabilities such as touch and swipe. A mobile app may also make use of the accelerometer and gyroscope of the device to affect navigation through physical user movement.

Android is a Linux-based operating system designed for touchscreen mobile devices such as smartphones and tablet computers.

App Store, an application store is a type of digital distribution platform for application software.

Apps are defined as: app, as an abbreviation for application, is a piece of software that can run on the internet, on your computer, or on your phone or other electronic device.

Cultural heritage site refers to a place, locality, natural landscape, settlement area, architectural complex, archaeological site, or standing structure that is recognised and often legally protected as a place of cultural and historical significance.

Digital in a very basic sense refers to the using and storing of data or information in the form of digital signals, relating to the use of computer technology.

Google Analytics (GA) is a service offered by Google that generates detailed statistics about a website's traffic sources.

iOS is a mobile operating system developed by Apple Inc.

Mobile device refers to a portable, handheld device that travels with the visitor, this can be tablets, PDAs, mobile phones, or smartphones.

Smartphone refers to a phone with an advanced operating system.

Unplug/unplugging refers to the conscious act of choosing to opt-out of digital engagement, this can be from smartphones, the internet, or any other digital device.

\footnotetext{
1 "Application." Merriam-Webster.com. Accessed June 27, 2016. http://www.merriam-webster.com/dictionary/application. 2 “App.” Dictionary.com. Dictionary.com Unabridged. Random House, Inc. Accessed June 27, 2016. http://www.dictionary.com/browse/app.
} 
User experience refers to a person's perceptions or responses that result from the use of a product, system or service.

User interface is the means by which people interact with a computer or device.

AHD - Authorised Heritage Discourse

AR - Augmented Reality

GLAM - Galleries, Libraries, Archives, and Museums

GPS - Global Positioning System

HNZ - Heritage New Zealand

ICOMOS - International Council on Monuments and Sites

IPENZ - Institute of Professional Engineers New Zealand

QR - Quick Response Code

UNESCO - United Nations Educational, Scientific and Gultural Organisation

VR - Virtual Reality

WHS - World Heritage Site 
Appendix 2 Visitor survey questions/Qualtrics

\section{Using Mobile Apps at heritage sites in Aotearoa New Zealand}

\section{Hello!}

My name is Jessica Aitken and I am a Masters student in Museum and Heritage Studies at Victoria University of Wellington. This research project is work towards my dissertation. The aim of the study is to investigate the relationship between digital technology and visitor experience at heritage sites. The objective is to gain the perspective of both visitors and heritage professionals to provide insight into the kind of experience mobile apps provide visitors.

\section{What can you do to help?}

I have selected two heritage sites to investigate, one in Christchurch and one in Wellington. I am looking for people to visit the heritage site in their city using the mobile app. Before your visit, you will answer a short online survey which includes questions about your previous heritage and digital interpretation experiences and basic demographic questions. Following your trip to the heritage site, I will interview you, either over the phone or via Skype, about your visit and your experience using the mobile app. The interview will be recorded and I will write it up later. I am not trying to gather positive or negative comments - but record real life experiences.

The visit to the heritage site can be as long or as short as you feel. The online survey will take approximately 10 minutes to complete and the phone interview will be around 30 minutes.

There are no restrictions or parameters on who can participate except that you must be older than 16 and be either in Wellington or Christchurch where the two chosen heritage sites are.

If you have any questions about the study or would like more information before you decide to participate, please feel free to email me on aitkenjess@myvuw.ac.nz.

\section{Are you interested?}

If this sounds like a project you are interested in being part of you can click the arrow below and take the online survey. After you submit your answers I will be in touch about the next step of the project.

I look forward to your responses and thank you in advance for your support.

\section{Questionnaire}

Following the New Zealand Framework for Cultural Statistics "heritage site" is defined as:

Buildings, structures, and areas of land, including archaeological sites, notable for their importance in New Zealand's history, and for their historic, cultural, spiritual, aesthetic, social or architectural value. They may be privately or publicly owned and are not necessarily open to the public.

- i.e. memorial, heritage walk, pa site, historic house or gardens, archaeological sites, sites of significance to Māori, including wāhi tapu.

\section{Which heritage site will you be visiting?}

High Street Stories 
IPENZ Wellington Heritage Walk

Have you experienced [High Street/Wellington CBD] as a heritage destination before? i.e. self-guided tour, group tours, audio tour, etc.

Yes [Please provide examples.]

No

Have you used the [High Street Stories/IPENZ] mobile app before?

Yes

No

Have you used any other heritage app before?

Yes [Please list which ones.]

No

Have you visited a heritage site in the past 12 months?

Yes [Please list the one/s you found most memorable.]

No

Any further comments you would like to make about your experience of heritage sites, heritage apps or mobile apps generally?

What is your age?

$\begin{array}{ll}16-19 & 50-59 \\ 20-29 & 60-69 \\ 30-39 & 70+ \\ 40-49 & \end{array}$

Do you own a smartphone?

Yes [Which kind of smartphone?]

No

Have you downloaded an app on your smartphone in the past 12 months?

Yes

No

How often do you use apps on your smartphone?

Daily

Weekly

Monthly

Yearly

Other 
Appendix 3 Email interview questions for heritage and design professionals

\section{Email Interview Questions for Heritage Professionals}

\section{Background:}

1. Tell me about your professional background and your role at [IPENZ/Heritage NZ].

2. How did you come to work on this project and what was your role specifically?

\section{Developing [High Street Stories/IPENZ Wellington Heritage Walking tour] mobile app:}

3. Tell me about how the app came to be developed.

Where did the idea come from? Who was involved?

4. What were the main objectives in designing the app?

Who was the app for? What did you hope they would get out of it?

5. The app is a [custom designed/uses the MyToursApp platform], what were the reasons for choosing a mobile template over a custom designed app/vice versa?

6. How did you find the process of designing the app?

Any specific challenges?

7. What do you wish you had known before starting the process?

What would you do differently?

\section{The Final Mobile App:}

8. How does the final mobile app meet the expectations you had at the start of the project? What do you think the app does well?

How do you think the app could do better?

9. Do you conduct any visitor studies specifically for the app?

i.e. How many downloads, visitor demographics, etc.

\section{Heritage in General:}

10. How do you think mobile apps compare to traditional interpretation techniques [i.e. brochures, graphic panels, signage]?

Final thoughts:

11. What does the future hold for this app? Say five years from now?

12. Any further comments you would like to make about the app specifically or digital technology and heritage generally? 


\section{Email Interview Questions for Glen Barnes CEO/Founder of My Tours}

\section{Background:}

1. Tell me about your professional background and your role at My Tours.

2. Tell me about how the My Tours App platform came to be created.

\section{Developing heritage mobile apps:}

3. On the website, you market the platform to the tourism, culture and heritage sector. Are there specific features you feel are needed for these particular industries?

4. How did you decide on the specific features available on the platform?

5. What features would you like to make available in the future?

6. What do you think the platform does well?

7. How do you think the platform could do better?

8. What do you wish heritage institutions knew before starting the app development process?

\section{Mobile Apps generally:}

9. What do you think are the biggest limitations to designing mobile apps at the moment?

\section{Final thoughts:}

10. Any further comments you would like to make about My Tours specifically, or digital technology and heritage generally? 


\section{Email Interview Questions for Gun Lee, Research Staff at HIT Lab}

\section{Background:}

1. Tell me about your professional background and your role at HIT Lab.

2. Tell me about the types of digital solutions you offer?

3. How did you come to work on the High Street Stories project and what was your role specifically?

\section{Developing heritage mobile apps:}

4. What do you wish heritage institutions knew before starting the app development process?

5. How do you approach developing a heritage app? Is it different from other types of projects?

6. What do you think the High Street Stories app does well?

7. How do you think the High Street Stories could do better?

8. What do you think is the greatest potential for heritage mobile apps?

\section{Mobile Apps generally:}

9. What do you think are the biggest limitations to designing mobile apps at the moment?

\section{Final thoughts:}

10. Any further comments you would like to make about your app/platform specifically or digital technology and heritage generally? 
Appendix 4 Prompts used for visitor interviews

\section{The mobile app experience:}

Tell me about your experience with IPENZ Walking Tour from when you first downloaded the app.

How did you find the process of downloading the app?

Tell me about your visit to [High Street/Wellington CBD] using the mobile app?

What did you do when you first arrived at the site?

Where did you start - did you catch the cable car up?

Which stories did you find most interesting?

Which stories did you find most engaging?

Which stories did you find most informative?

Do you remember any particular feelings while visiting the heritage site?

Did you read any of the extra biographies or stories, or focus on the main entry?

Have you used the app while not at the actual site, after the tour?

Were there sites or stories in the app that you have wanted to learn about?

Which features of the app did you enjoy the most, i.e. the videos, the photos, map?

How did you find navigating throughout the tour? Getting from place to place.

How do your feelings about the heritage site compare after using the app?

After using the app, what do you feel about the heritage site? Has your opinion changed?

\section{Evaluate:}

Would you recommend the app to a friend? Why/why not?

Would you visit again? Why/why not?

If you were to rate this app what score would you give it out of 10 ? Why?

What do you think the app does well?

What would you change about the app?

\section{General heritage experiences:}

What makes a visit to a heritage site enjoyable to you?

What kind of experience do you seek at heritage sites?

What do you want to get out of your visits to historic sites?

What is the most important part of visiting a heritage site, for you?

How did this experience compare with previous heritage experiences you have had before?

Refer to prior self-complete questionnaire.

\section{Concluding question:}

Any further comments about the mobile app and your experience at the heritage site? 